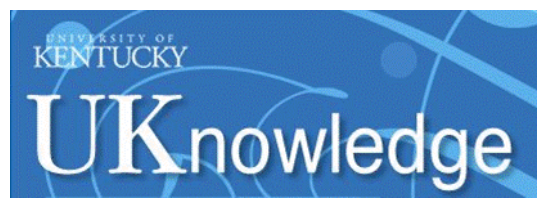

University of Kentucky

UKnowledge

\title{
PERSONALITY-RELATED PROBLEMS IN LIVING: AN EMPIRICAL APPROACH
}

\section{Stephanie N. Mullins-Sweatt}

University of Kentucky, Stephanie.Sweatt@gmail.com

Right click to open a feedback form in a new tab to let us know how this document benefits you.

\section{Recommended Citation}

Mullins-Sweatt, Stephanie N., "PERSONALITY-RELATED PROBLEMS IN LIVING: AN EMPIRICAL APPROACH" (2008). University of Kentucky Doctoral Dissertations. 628.

https://uknowledge.uky.edu/gradschool_diss/628

This Dissertation is brought to you for free and open access by the Graduate School at UKnowledge. It has been accepted for inclusion in University of Kentucky Doctoral Dissertations by an authorized administrator of UKnowledge. For more information, please contact UKnowledge@lsv.uky.edu. 
Abstract of Dissertation

Stephanie N. Mullins-Sweatt

The Graduate School University of Kentucky 2008 
PERSONALITY-RELATED PROBLEMS IN LIVING: AN EMPIRICAL APPROACH

ABSTRACT OF DISSERTATION

A dissertation submitted in partial fulfillment of the requirements for the degree of Doctor of Philosophy in the College of Arts and Sciences at the University of Kentucky

By

Stephanie N. Mullins-Sweatt

Lexington, Kentucky

Director: Dr. Thomas A. Widiger, Professor of Psychology

Lexington, Kentucky

2008

Copyright (C) Stephanie Nicole Mullins-Sweatt, 2008 


\section{ABSTRACT OF DISSERTATION}

\section{PERSONALITY-RELATED PROBLEMS IN LIVING: AN EMPIRICAL APPROACH}

Research has suggested that the Five Factor Model (FFM) is useful in describing personality pathology as well as personality traits. However, there appears to be disproportionate implications of the five domains for problems in living. Previous empirical research concerning the differential direction and magnitude of the relationship of the FFM domains to problems in living and personality disorder symptomatology has perhaps been limited in part by the use of a measure of the FFM that itself includes a disproportionate representation of maladaptive personality functioning across the domains. The current study also tests the hypothesis that the relationship of the FFM domains to problems in living parallels the definition of personality disorder as provided in the American Psychiatric Association's (2000) diagnostic manual, concerning social impairment, occupational impairment, and distress. These hypotheses were tested in a sample of 79 persons who were within psychiatric treatment. The current study indicated that problems in living relate to the FFM domains in a meaningful manner and that these relationships correspond to the definition of personality disorder. Implications of the findings for future research are discussed.

Keywords: Five-Factor Model, personality disorders, problems in living, dysfunction, impairment

Stephanie Nicole Mullins-Sweatt Student's Signature

July 10,2008

Date 
PERSONALITY-RELATED PROBLEMS IN LIVING: AN EMPIRICAL APPROACH

\author{
By
}

Stephanie N. Mullins-Sweatt

Thomas A. Widiger

Director of Dissertation

David T.R. Berry

Director of Graduate Studies 


\section{RULES FOR THE USE OF DISSERTATIONS}

Unpublished dissertations submitted for the Doctor's degree and deposited in the University of Kentucky Library are as a rule open for inspection, but are to be used only with due regard to the rights of the authors. Bibliographical references may be noted, but quotations or summaries of parts may be published only with the permission of the author, and with the usual scholarly acknowledgments.

Extensive copying or publication of the dissertation in whole or in part also requires the consent of the Dean of the Graduate School of the University of Kentucky.

A library that borrows this dissertation for use by its patrons is expected to secure the signature of each user.

$\underline{\text { Name }}$

$\underline{\text { Date }}$ 


\section{DISSERTATION}

Stephanie N. Mullins-Sweatt

The Graduate School

University of Kentucky

2008 
PERSONALITY-RELATED PROBLEMS IN LIVING: AN EMPIRICAL APPROACH

\title{
DISSERTATION
}

A dissertation submitted in partial fulfillment of the requirements for the degree of Doctor of Philosophy in the College of Arts and Sciences at the University of Kentucky

\author{
By \\ Stephanie N. Mullins-Sweatt \\ Lexington, Kentucky
}

Director: Dr. Thomas A. Widiger, Professor of Psychology

Lexington, Kentucky

2008

Copyright (C) Stephanie Nicole Mullins-Sweatt, 2008 
To my parents who truly instilled in me an appreciation for knowledge and a consummate work ethic. 


\section{ACKNOWLEDGEMENTS}

While there are many people who have influenced my academic career, my parents' insistence on the importance of education is certainly the driving force behind my choices. Their provision of unwavering support and a wealth of intellectual resources is ever-appreciated. I would also like to thank the rest of my family and friends who encouraged me to achieve my goals and were always there for me when I thought I could not finish. Specifically, I owe much appreciation to my husband, Chad, who always believed in me (often more than I believed in myself!) and pushed me toward excellence.

I am thankful to the friends I have made in graduate school who have helped me through arduous times. I owe special gratitude to my classmates who have been with me every step of the way and my lab mates who became my friends and colleagues. I am also sincerely appreciative of my friends away from school, who often provided me with much-needed balance and perspective.

My experiences at the University of Kentucky have been excellent, due in large part to the wonderful advisement I have received from the clinical faculty. I would like to especially thank the individuals who have served on my committees, Dr. Greg Smith, Dr. David Berry, Dr. Ruth Baer, and Dr. Don Lynam whose assistance in my program of research has improved my capabilities as a future academician.

Finally, I cannot begin to express the extreme gratitude I have for my advisor, Dr. Thomas Widiger. It was through the work of Dr. Widiger that my interest in personality 
disorders was first realized almost a decade ago. His patience with me throughout my scholastic journey from an undergraduate researcher to a doctoral candidate gains my most sincere appreciation. His encouragement, assistance, support, and feedback has enhanced my abilities more than I ever imagined. His generosity provided the financial support for this along with several other projects. I know that I can never thank him enough for the numerous opportunities he has given me. 


\section{TABLE OF CONTENTS}

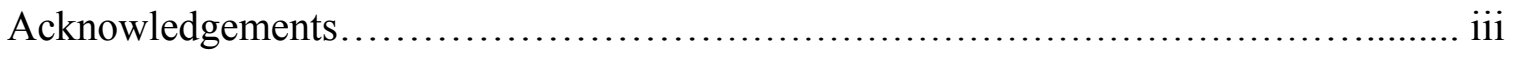

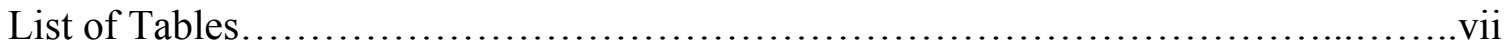

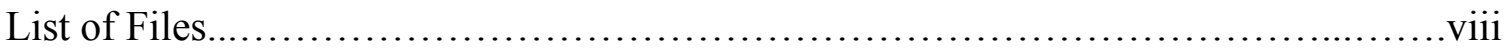

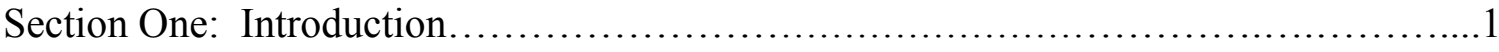

FFM Profile in Problems in Living ........................................

The Nature of the Impairments........................................... 4

Section Two:

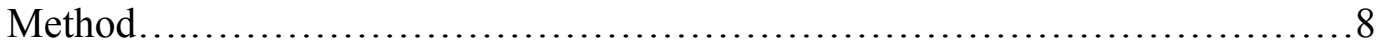

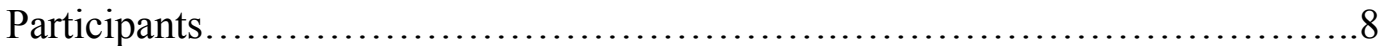

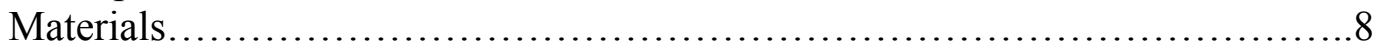

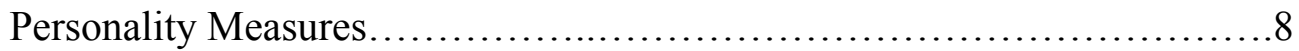

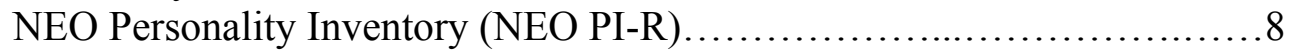

Experimentally Revised NEO Personality Inventory (NEO PI-R) ........... 8

Impairment/distress measure ............................................ 8

Brief Symptom Inventory (BSI) ........................................

Couple's Critical Incidents Checklist (CCIC) ..................................

Inventory of Interpersonal Problems (IIP-64) ............................. 9

Kennedy Axis V (K Axis)............................................. 9

Personal Problems Checklist for Adults (PPCA) ......................... 9

Personality disorder measure............................................ 8

Personality Diagnostic Questionnaire (PDQ-4) ......................... 9

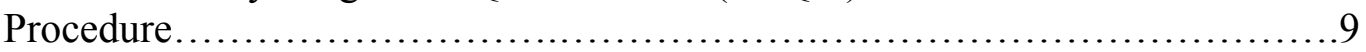

Section Three:

Results.............................................................. 10

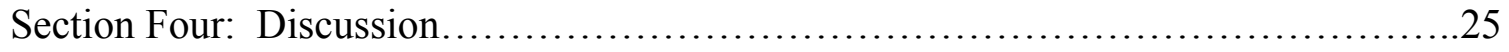

Assessment of Maladaptive Variants.......................................26

Definition of Personality Disorder..........................................27

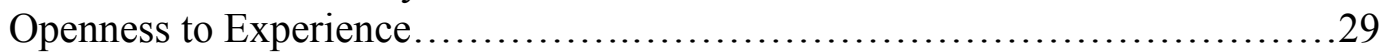

Treatment Implications................................................. 31

Characteristic Maladaptations and Adaptations..................................32

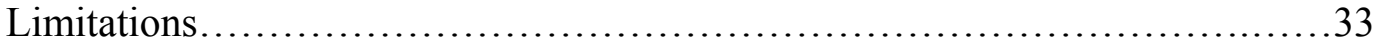

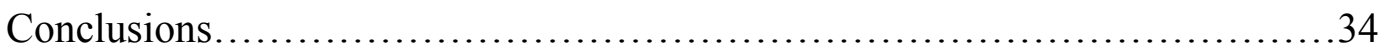

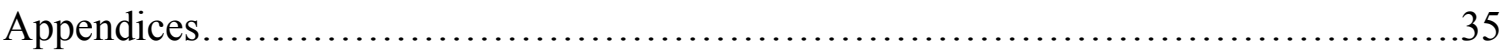

Appendix A: Correlations of the Experimentally-Altered Version of the NEO PI-R Domains with Scales of Affective Impairment.................................35 Appendix B: Hierarchical Regression Analyses for Scales of Social Impairment 
(with Experimental NEO PI-R) ......................................... 36 Appendix C: Correlations of the Experimentally-Altered Version of the NEO PI-R Domains with Scales of Occupational Impairment..............................37

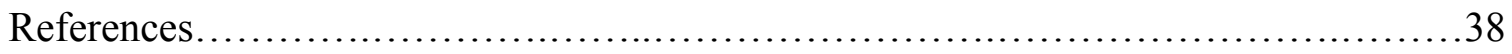

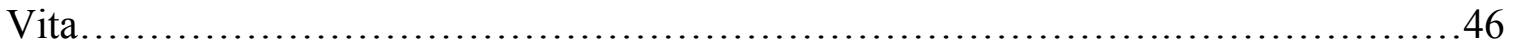




\section{LIST OF TABLES}

Table 1.1, Domains and Facets of the Five-Factor Model...............................

Table 3.1, Descriptive Statistics for Respective Instruments......................... 13

Table 3.2, Individual Item Level Correlations with Domains of the NEO PI-R...........15

Table 3.3, Individual Item Level Correlations with Domains of the ExperimentallyAltered Version of the NEO PI-R Domains.........................16

Table 3.4, Correlations of the NEO PI-R Domains with Scales of Affective Impairment.............................................. 17

Table 3.5, Hierarchical Regression Analyses for Scales of Affective Impairment (with NEO PI-R)..............................................18

Table 3.6, Correlations of the NEO PI-R Domains with Scales of Social Impairment....19

Table 3.7, Correlations of the Experimentally-Altered Version of the NEO PI-R Domains with Scales of Social Impairment................................20

Table 3.8, Hierarchical Regression Analyses for Scales of Social Impairment (with NEO

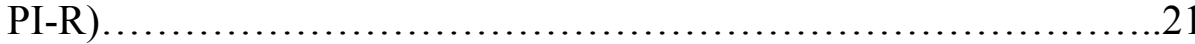

Table 3.9, Further Hierarchical Regression Analyses for Scales of Social Impairment (with NEO PI-R) ...........................................22

Table 3.10, Correlations of the NEO PI-R Domains with Scales of Occupational Impairment................................................23

Table 3.11, Hierarchical Regression Analyses for Scales of Occupational Impairment (with NEO PI-R) ............................................24 


\section{LIST OF FILES}

sweattdissertation.pdf.......................................................... 
Section One: Introduction

The five-factor model (FFM) of personality was derived originally from studies of the English language to identify those traits that are most significant in describing oneself and other persons (Digman, 1990; John \& Srivastava, 1999). Studies of English and many other languages have generally supported the identification of five broad domains of personality: extraversion (surgency or positive affectivity) versus introversion, agreeableness versus antagonism, conscientiousness versus undependability, neuroticism (emotional instability or negative affectivity) versus emotional stability, and openness to experience (intellect or unconventionality) versus closedness to experience, referred to as the FFM or the Big Five (Ashton \& Lee, 2001). Each of these five broad domains has been differentiated into six more specific facets by Costa and McCrae (1995). For example, Costa and McCrae suggest that the domain of agreeableness (vs. antagonism) can be differentiated into the more specific facets of trust, straightforwardness, altruism, compliance, modesty, and tender-mindedness. Table 1.1 provides a list of the five domains and thirty facets of the FFM.

There is a great deal of empirical support for the construct validity of the facet and domain levels of the FFM. This has been shown with convergent and discriminant validation in self-report, peer ratings, and spouse ratings (McCrae, Stone, Fagan, \& Costa, 1998), temporal stability (McCrae \& Costa, 2003; Roberts \& DelVecchio, 2000), generalizability across age, gender, and culture (McCrae \& Allik, 2002), and heritability (Yamagata et al., 2006). The FFM has also been used successfully as an integrative model for personality description in a number of applied fields, including health psychology (Artistico, Baldassarri, Lauriola \& Laicardi, 2000) and industrial organizational psychology (Hogan \& Holland, 2003) as well as developmental research such as child and adolescent temperament research (Caspi, Roberts, \& Shiner, 2005) and aging (Costa, McCrae \& Siegler, 1999).

The FFM has also been shown to be useful in predicting important life outcomes, as outlined in an extensive review by Ozer and Benet-Martinez (2006). They indicated that all five domains of the FFM often provide contributions to successful life outcomes, and, perhaps most importantly, these relationships are relatively specific for each domain. For example, subjective well-being was related most strongly to high extraversion (high positive affectivity) and low neuroticism (low negative affectivity). Similarly, job performance was most strongly related to the domain of conscientiousness whereas occupational satisfaction was primarily related to extraversion and emotional stability (low neuroticism). The domains of agreeableness and extraversion predicted social acceptance, and antagonism (low agreeableness) was the primary domain related to relationship dissatisfaction, conflict, and criminality. Finally, openness to experience was the principal domain related to existential/paranormal beliefs, creativity, and educational level.

It has also been proposed that each of the personality disorders included within the American Psychiatric Association's (APA) Diagnostic and Statistical Manual of Mental Disorders (DSM-IV-TR; APA, 2000) can be understood as maladaptive variants of these personality traits that are evident in all persons (Ball, 2001; O'Connor, 2005; Ostendorf, 2000). Widiger and Costa (2002) summarized the results of over 50 studies that supported the hypothesis that the DSM-IV-TR personality disorders could be understood as maladaptive variants of the domains and facets of the FFM. Quite a few 
more studies have since been published (Clark, 2007; Mullins-Sweatt \& Widiger, 2006; Widiger \& Lowe, 2007). In a meta-analysis examining fifteen independent samples, Saulsman and Page (2004) concluded that "each of the personality disorders shows associations with the five-factor model that are meaningful and predictable given their diagnostic criteria" (p. 1075). Livesley (2001) concluded on the basis of his review of the research that "multiple studies provide convincing evidence that the DSM personality disorders diagnoses show a systematic relationship to the five-factors and that all categorical diagnoses of DSM can be accommodated within the five-factor framework" (p. 24). As expressed by Clark (2007), "the five-factor model of personality is widely accepted as representing the higher-order structure of both normal and abnormal personality traits" (p. 246) and the "DSM personality disorders can be characterized with the FFM conceptually... and empirically" (p. 230). These are compelling endorsements as they are provided by authors of alternative dimensional models (Livesley, 2007; Clark et al., 2007).

FFM Profile in Problems in Living

Missing from much of this prior research, however, has been a fuller appreciation or systematic consideration of the differential nature of the relationships of personalityrelated problems in living to the five domains of the FFM. In theory, all five domains, and all ten poles of the five domains, have implications for maladaptive personality functioning (Lynam \& Widiger, 2001; Widiger, Costa, \& McCrae, 2002). Nevertheless, a consistent finding across the existing research has been a much smaller contribution of openness to experience (Clark \& Livesley, 2002; O'Connor, 2005; Saulsman \& Page, 2004). It also appears to be the case that the remaining four domains do not themselves have equal implications for maladaptivity. Widiger and Costa (1994) suggested early on that "each dimension of personality will not have the same degree of implications for maladaptivity. The same degree of neuroticism (negative emotionality), extraversion (positive emotionality), or conscientiousness (constraint) is unlikely to be associated with the same degree of maladaptivity" (p. 84). The more recent meta-analysis conducted by Saulsman and Page (2004) showed that "the dimensions of neuroticism and agreeableness are the most prominent and consistent across the varying disorders as indicated by substantial and directionally consistent effect sizes" (p. 1076).

McCrae, Lockenhoff, and Costa (2005) systematically coded lists of problems in living as to whether they were relevant to personality and then whether they considered them to be associated with an FFM domain or facet. McCrae et al. selected instruments that were considered to be reasonably comprehensive in their coverage of various problems in living, including the Computerized Assessment System for Psychotherapy Evaluation and Research (CASPER; Farrell \& McCullough-Vaillant, 1996), the Couples Critical Incidents Checklist (CCIC; Piedmont \& Piedmont, 1996), the Inventory of Interpersonal Problems (IIP-64; Horowitz, Alden, Wiggins, \& Pincus, 2000), the Personal Problems Checklist for Adults (PPCA; Schinka, 1985), and the Shedler and Westen Assessment Procedure (SWAP-200; Shedler \& Westen, 1998). Dr. Lockenhoff examined all 663 items contained within these five instruments and assigned each item to a respective facet of the FFM on a subjective, rational basis. Items were first assigned to the low or high pole of a domain, and then, if possible, to the low or high pole of a specific facet within that domain. Most of the items in all five inventories were classifiable. For example, they were able to classify $98 \%$ of the CCIC, $100 \%$ of the IIP- 
64 , and $61 \%$ of the PPCA items, indicating that, in theory, most of the problems in living assessed within these inventories might be understandable as problems secondary to maladaptive personality functioning.

In addition, there was a disproportional assignment across the domains, as more problems in living were identified in the domains of neuroticism and agreeableness (i.e., $28 \%$ and $28 \%$, respectively) than extraversion, openness to experience and conscientiousness (i.e., $17 \%, 13 \%$, and $15 \%$, respectively), consistent with the metaanalysis of personality disorder research by Saulsman and Page (2004). Additionally, problems in living were not balanced across the poles of each domain as "high neuroticism is associated with more than ten times as many problems as low neuroticism, and low agreeableness is associated with nearly three times as many problems as high agreeableness" (McCrae et al., 2005, p. 277). However, a significant limitation of this study was that the findings were based simply on the personal opinions of the authors. None of the instruments were correlated empirically to any independent FFM measure. One of the purposes of the current study was to determine whether these problems in living are in fact distributed in a disproportionate manner as suggested by the hypotheses of McCrae et al. (2005).

Consistent with McCrae et al. (2005), Haigler and Widiger (2001) reported a similar differential distribution of maladaptivity in their coding of items of the most frequently used measure of the five-factor model, the NEO Personality InventoryRevised (NEO PI-R; Costa \& McCrae, 1992). In this study, they determined the direction of adaptivity versus maladaptivity of NEO PI-R items by first independently judging which direction of the scoring was adaptive or desirable for each of the 240 items. For example, they judged whether it was more desirable or adaptive to agree or disagree with the item "I keep my belongings neat and clean." They indicated that $98 \%$ of the NEO-PI$\mathrm{R}$ items describing high neuroticism refer to socially undesirable or maladaptive traits; $90 \%$ of the low extraversion; $88 \%$ of low openness to experience; $83 \%$ of the low agreeableness items; and $90 \%$ of the low conscientiousness items.

In other words, the disproportionate representation of NEO PI-R items that assess for undesirable or maladaptive personality traits do appear to roughly parallel the empirical relationships obtained within the research literature and with the coding of problems in living by McCrae et al. (2005). However, the results of Haigler and Widiger (2001) can also be interpreted as being problematic for the NEO PI-R assessment of the maladaptive variants of some of the poles of the FFM. The NEO PI-R is providing substantially less representation of maladaptive variants of high extraversion, high agreeableness, high conscientiousness, low neuroticism, and high openness to experience than the opposite poles of these domains (Haigler \& Widiger, 2001). The NEO PI-R is not providing equal fidelity to the maladaptive variants of personality functioning. As acknowledged by Widiger and Costa (1994), "The NEO PI-R was constructed primarily for the assessment of the normal (adaptive) range of personality functioning, and it may not provide adequate coverage of the extreme, maladaptive variants of each of the factors" (pp. 87-88). For example, Reynolds and Clark (2001) reported that the 15 maladaptive personality scales from the Schedule for Nonadaptive and Adaptive Personality (SNAP; e.g., Mistrust, Manipulation, Aggression, Self-Harm, and Detachment) outperformed the NEO-PI-R facet scales (e.g., Warmth, Compliance, Openness to Ideas, and Competence) in predicting personality disorder symptoms. They 
suggested that this occurred largely because "the FFM measures assess normal-range traits [whereas] the SNAP primarily assesses extreme variants of normal-range traits that are maladaptive and clinically relevant" (Reynolds \& Clark, 2001, p. 218). In other words, it was not that the SNAP and the NEO-PI-R were assessing qualitatively different domains of personality functioning. "The maladaptive personality traits assessed by the SNAP were strongly represented in the facet scales of the NEO-PI-R" (Reynolds \& Clark, 2001, p. 216). However, the SNAP, relative to the NEO-PI-R, is providing more focus on the maladaptive variants of FFM personality traits.

This was also demonstrated empirically by Haigler and Widiger (2001). They altered each NEO PI-R item to reverse the direction of adaptivity (or maladaptivity) without changing the direction in which the item was keyed or otherwise altering the content of the item. Items were revised to suggest maladaptivity by inserting words such as "excessively," "too much," or "preoccupied with" to alter the behaviors described within the item into a maladaptive variant of the same trait. For example, the conscientiousness item, "I keep my belongings neat and clean," was revised to "I keep my belongings excessively neat and clean." They administered both the original NEO PI$\mathrm{R}$ and the experimentally-altered NEO PI-R to the same respondents, along with three measures of personality disorder [i.e., the Schedule for Nonadaptive and Adaptive Personality (SNAP; Clark, 1993), Personality Diagnostic Questionnaire-4 (PDQ-4; Hyler, 1994), and Minnesota Multiphasic Personality Inventory-2 (MMPI-2 PD; Morey, Waugh, \& Blashfield, 1985)]. Altering the content of items to have them describe excessive, problematic, or otherwise maladaptive variants of the original content produced substantial increases in correlations of domains of the FFM for which the original NEO PI-R lacked adequate representation of these maladaptive variants. For example, correlations between NEO PI-R conscientiousness and the three obsessive-compulsive personality disorder scales increased from .27, -.15, and -.02 (with the SNAP, MMPI-2 PD, and PDQ-4, respectively) to .69, .47, and .69, respectively; and correlations between NEO PI-R agreeableness and the three dependent personality disorder scales increased in correlation from $.04, .17$, and .04 to $.57, .66$, and .45 , respectively. In sum, a study attempting to identify the direction and degree of problems in living associated with the five domains of the FFM, and their respective 10 poles, should include comparable assessments of the maladaptive variants of each pole. Studies which fail to provide an adequate assessment of the maladaptive variants of (for instance) high agreeableness and high conscientiousness may fail to identify problems in living associated with these domains of the FFM.

\section{The Nature of the Impairments}

Beyond a differentiation among the domains of the FFM with respect to the degree and direction of their relationship with problems in living are differences in the quality of these problems. Personality disorders are defined in DSM-IV-TR as involving "clinically significant distress or impairment in social, occupational, or other important areas of functioning" (APA, 2000, p. 689). The FFM of personality disorder suggests a reorganization of personality disorder symptomatology that could in fact be closely consistent with this DSM-IV-TR definition. An additional purpose of the current study is to determine whether the structure of the FFM also has specific implications with respect to impairments in social and occupational functioning and psychological distress. 
The structure of the FFM may correspond well with three basic components of personality impairment that are identified within the APA (2000) definition of mental disorder. The domain of neuroticism or negative affectivity might be relatively specific to impairments of distress. High neuroticism would likely contribute to various forms of affective dysregulation, including anxiousness, depressiveness, anger, and instability of mood. FFM extraversion and agreeableness might be relatively specific to social impairment, as these are the domains of the FFM that concern matters of interpersonal relatedness (McCrae \& Costa, 1989; Wiggins \& Pincus, 1989). Maladaptive variants of the traits within these two domains may be more specifically associated with marital, family or other forms of interpersonal dysfunction and relationship problems. The domain of conscientiousness concerns matters of competence, organization, selfdiscipline, and achievement-striving (Costa \& McCrae, 1992). Maladaptive variants of these traits might then be more specifically related to behavior that affects work and career (occupational impairment), with laxness, irresponsibility, and negligence at one pole and a maladaptively excessive perfectionism and workaholism at the opposite pole.

It is noteworthy, however, that no specific hypotheses would be made for social and occupational impairment and personal distress with respect to openness to experience, consistent with its relatively weaker relationship with personality disorder symptomatology reported in prior research (Saulsman \& Page, 2004). High levels of the domain of openness to experience, however, could have specific implications for impaired reality testing, magical thinking, and perceptual aberrations (i.e., cognitive dysfunction), but these are not specifically identified within the APA (2000) definition of personality disorder.

Support for the hypothesized correspondence of the four domains of the FFM with the APA (2000) three components of personality impairment is suggested in the review by Ozer and Benet-Martinez (2006) of the important life outcomes associated with the five domains of the FFM. As previously indicated, they suggested that all five domains of the FFM have been shown to be useful in predicting domain-specific life outcomes. More specifically, subjective well-being was related most strongly to low neuroticism. The domains of agreeableness and extraversion predicted social acceptance, and low agreeableness was the primary domain related to relationship dissatisfaction, conflict, and criminality. Job performance was most strongly related to the domain of conscientiousness. It is also worth noting that openness to experience was the principal domain related to existential/paranormal beliefs, creativity, and educational level. However, inconsistent with a straightforward relationship of the four domains of the FFM with the three components of personality disorder impairment is that Ozer and BenetMartinez (2006) also reported that subjective well-being was related strongly to high extraversion and occupational satisfaction was primarily related to extraversion and low neuroticism.

In sum, it was also hypothesized in the current study that problems in living that concern social impairment, occupational impairment, or personal distress, the three components of an APA (2000) personality disorder, will relate with particular FFM personality domains in a relatively specific manner. More precisely, dysfunctions in interpersonal relationships will be primarily related to the domains of agreeableness and extraversion; affective impairment (i.e., distress) will be most closely related to the neuroticism domain; and occupational impairment will be related primarily to the domain 
of conscientiousness. These specific associations will be particularly evident when the assessment of the FFM is conducted with scales that are predominated by maladaptive variants of the respective FFM traits.

Copyright (C) Stephanie Nicole Mullins-Sweatt, 2008 
Table 1.1

Domains and Facets of the Five-Factor Model

Neuroticism vs. Emotional Stability

Anxiousness vs. Unconcerned

Angry hostility vs. Dispassionate

Depressiveness vs. Optimistic

Self-Consciousness vs. Shameless

Impulsivity vs. Restrained

Vulnerability vs. Fearless

Extraversion vs. Introversion

Warmth vs. Coldness

Gregariousness vs. Withdrawal

Assertiveness vs. Submissiveness

Activity vs. Passivity

Excitement-Seeking vs. Lifeless

Positive Emotions vs. Anhedonia

Openness vs. Closedness

Fantasy vs. Concrete

Aesthetics vs. Disinterest

Feelings vs. Alexithymia

Actions vs. Predictable

Ideas vs. Closed-Minded

Values vs. Dogmatic

Agreeableness vs. Antagonism

Trust vs. Mistrust

Straightforwardness vs. Deception

Altruism vs. Exploitative

Compliance vs. Aggression

Modesty vs. Arrogance

Tender-Mindedness vs. Tough-Mindedness

Conscientiousness vs. Disinhibition

Competence vs. Laxness

Order vs. Disorderly

Dutifulness vs. Irresponsibility

Achievement-Striving vs. Lackadaisical

Self-Discipline vs. Negligence

Deliberation vs. Rashness 


\section{Participants}

\section{Section Two: Method}

The sample consisted of 79 individuals ( 62 females, 17 males) who identified themselves as having experienced "significant problems at work, school, or in relationships" and/or "significant distress." Four individuals were dropped due to invalid data. Ages ranged from 18 to $58(\mathrm{M}=29.46, \mathrm{SD}=10.84)$ and $78.5 \%$ were Caucasian. Individuals were recruited from advertisements in the newspaper and flyers placed at treatment facilities in the community of Lexington, Kentucky. All individuals had previously been in psychological treatment. This sample was diagnostically heterogeneous, composed of patients with a variety of Axis I and II diagnoses including alcohol dependence, affective disorders, and anxiety disorders, as well as personality pathology. Excluded from the sample were any persons reporting a history of any psychotic disorder. Fifty-two percent of the sample was currently prescribed psychotropic medication and $29 \%$ had been previously hospitalized at least once in their life. Materials

Personality measures

NEO Personality Inventory-Revised (NEO PI-R; Costa \& McCrae, 1992). The NEO PI-R is a 240-item questionnaire designed to provide a self-report measure of the FFM. Participants rate each item on a 5-point Likert scale. This instrument was designed to assess five domains (neuroticism, extraversion, openness to experience, agreeableness, and conscientiousness) and six narrower facets of the FFM. Internal consistency coefficients have ranged from .86 (agreeableness) to .92 (neuroticism), and 7-year testretest reliability coefficients have ranged from .63 to .81 (Costa \& McCrae, 1992).

Experimentally Revised NEO Personality Inventory-Revised (NEO-X; Haigler \& Widiger, 2001). The NEO-X is a 240-item questionnaire that was designed to complement the NEO PI-R's assessment of FFM maladaptivity. The NEO-X includes the same content as the original NEO PI-R but each item was revised to reflect the opposite direction of maladaptivity (i.e., the adaptive pole of each item was revised to reflect a maladaptive level of functioning, or the maladaptive pole was revised to reflect an adaptive level of functioning). For example, as previously noted, the NEO PI-R conscientiousness item, "I keep my belongings neat and clean," was revised to "I keep my belongings excessively neat and clean." Other example revisions include "I really like most people I meet" was revised to "I like most people I meet so much that I have been described as careless" (Agree = maladaptive extraversion; Disagree $=$ adaptive introversion) and "I tend to be cynical and skeptical of others' intentions" was revised to "Some degree of skepticism regarding the intentions of others is healthy" (Agree = adaptive antagonism; Disagree $=$ maladaptive agreeableness).

Impairment/distress measures

Brief Symptom Inventory (BSI; Derogatis, 2004). The BSI is a 53-item self-report inventory designed to provide an overview of an individual's psychological symptoms and intensity. This inventory provides three global symptom indices as well as nine symptoms scales (e.g., anxiety, paranoid ideation).

Couple's Critical Incidents Checklist (CCIC; Piedmont \& Piedmont, 1996). The CCIC is a screening measure designed to assess the extent and type of dissatisfaction an individual is experiencing with his/her spouse, thereby identifying areas of conflict in close relationships. The 135 items describe specific behaviors and personal qualities of 
the partner (e.g., complains a lot) and are grouped into six sections concerning different areas of conflict (e.g., interpersonal, personal reliability). Participants check all items that are perceived as sources of tension in their relationship. Empirical evidence suggests that spouse's CCIC ratings of a target person are moderately correlated with self-and observer-rated NEO PI-R scores (Kosek, 1998).

The Inventory of Interpersonal Problems (IIP-64; Horowitz, Alden, Wiggins, \& Pincus, 2000) is a self-report measure designed to screen for interpersonal problems and the level of distress associated with them. This measure was guided by the interpersonal circumplex model. Items are grouped into six subscales assessing different domains of interpersonal functioning (e.g., assertiveness). On 39 of the 64 items, participants are asked to rate behaviors that are "hard to do"; the remaining 25 items ask for interpersonal behaviors that the participants "do too much". Participants rate how much they experience each problem on a five-point scale.

Kennedy Axis V (K Axis; Kennedy, 2003). The K Axis is a multidimensional measure of patient functioning that assesses 10 global measures of functioning that includes psychological impairment, social skills, and occupational impairment.

Personal Problems Checklist for Adults (PPCA; Schinka, 1985). The PPCA assesses clinically relevant problems in everyday functioning. The 208 items are grouped into 13 areas of functioning (i.e., social, appearance, vocational, family/home, school, financial, religion, emotional, legal, sexual, health/habits, attitude, and crises) and briefly describe concrete problems (e.g., not having a job, getting too emotional). Individuals check all items that trouble them and also circle the most important problems.

Personality disorder measure

Personality Diagnostic Questionnaire-4 (PDQ-4; Hyler, 1994). The PDQ-4 is a 99-item true/false self-report inventory designed to screen for the ten personality disorders found in the DSM-IV as well as two additional disorders located in the appendix. This inventory assesses both overall personality disturbance and specific personality diagnoses. Internal consistency coefficients reported by Hyler et al. (1989) ranged from .56 (schizoid) to .84 (dependent).

Procedure

Participants were recruited from advertisements in the newspaper and flyers placed at treatment facilities (i.e., Comprehensive Care, Harris Psychological Services Center, Hope Center, and Private Practitioners) and additional locations (i.e., hospitals and pharmacies). The advertisements and flyers indicated that individuals who have ever experienced "significant problems at work, school, or in relationships" or "significant distress" were invited to participate. Individuals interested in participating contacted the researcher's office for more information. When an individual called, he/she underwent a brief telephone screening that assured the individual was appropriate for the study as well as provided additional information regarding the purpose and logistics of the study. Participants completed the packets of questionnaires which took approximately two hours to finish. Individuals were reimbursed $\$ 15$ for their time and effort.

Copyright (C) Stephanie Nicole Mullins-Sweatt, 2008 
Section Three: Results

The mean scores of the personality measures and impairment instruments can be found in Table 3.1. A total score of 30 or more on the PDQ-4 is considered to indicate the presence of significant personality disturbance (Bagby \& Farvolden, 2004); the average total score on the PDQ-4 obtained in the current study was $32.17(\mathrm{SD}=16.19)$ with $56.2 \%$ of the participants receiving a score above 30 . Elevations on the PDQ-4 suggest that the sample was characterized primarily by borderline, paranoid, obsessivecompulsive, narcissistic, schizotypal, and avoidant symptomatology, with relatively less representation of schizoid, histrionic, dependent, and antisocial symptomatology.

Information on the differential nature of the relationships of problems in living to the five domains of the NEO PI-R can be found in Table 3.2. This table presents the total number of individual item correlations for each measure with the NEO PI-R domain scales. It should be noted that all items of the impairment scales (e.g., BSI and CCIC) are keyed in the direction of maladaptivity; therefore, both positive and negative correlations which achieved significance are reported. As can be seen in Table 3.2, all three $\mathrm{K}$-axis indicators of impairment were associated with at least one domain of the FFM, $80 \%$ of the IIP indicators, and $77 \%$ of the BSI, but only $36 \%$ of the CCIC and $41 \%$ of the PPCA.

The domain and pole which were associated with the greatest amount of impairment was high neuroticism. In addition, consistent with expectations, impairment was also differentially related to low conscientiousness, low extraversion, and low agreeableness. However, inconsistent with expectations, more indicators of impairment were associated with high, rather than low, openness to experience (primarily all from the PPCA).

Table 3.3 provides the same analyses with the experimentally altered version of the NEO PI-R (NEO-X). The proportion of items that were correlated significantly with the domains of the FFM did not change. In addition, consistent with expectations, significantly more items were now correlated with high extraversion and high agreeableness rather than with the low poles of these domains. In fact, the proportional representation was essentially reversed. However, inconsistent with expectations, no reversal occurred for neuroticism, openness, or conscientiousness.

Table 3.4 provides the correlations of the scales concerning affective distress with the five domains of the FFM. It is evident from Table 3.4 that all of the measures of psychological distress were significantly correlated with the NEO PI-R domain of neuroticism. There was little to no significant correlations with extraversion, openness, or agreeableness. However, a majority of the impairment measures also showed significant correlations with low conscientiousness.

In order to assess if conscientiousness was uniquely contributing to these relationships, a series of hierarchical regression analyses were conducted (see Table 3.5). In the first series of analyses, the NEO PI-R domain of conscientiousness was entered in the first step and NEO PI-R neuroticism was entered in the second step. As would be expected, in each of the cases where conscientiousness was significantly related to a measure of impairment, conscientiousness was able to describe a significant proportion of variance, ranging from $6 \%$ (BSI Phobia) to 21\% (PPCA Emotional Problems). Neuroticism, however, consistently obtained incremental validity over each conscientiousness scale in accounting for variance in affective impairment. In contrast, 
when neuroticism was entered in the first step, conscientiousness was unable to account for any significant proportion of variance above and beyond neuroticism.

Table 3.6 provides the correlations of the measures of social impairment with the domains of the FFM. Consistent with expectations, significant (negative) correlations were obtained with BSI Paranoia, IIP Competitive/Exploitive, IIP Blunt/Aggressive, IIP Skeptical/Distrustful, and K-Axis Social Impairment. However, inconsistent with FFM expectations (McCrae et al., 2005), no significant positive correlations were obtained with IIP Docile/Dependent, IIP Responsible/Over-generous, or PPCA Social Problems. IIP Modest/Self-Effacing, IIP Cooperative/Over-conventional, CCIC Interpersonal Problems, and CCIC Cooperativeness Problems correlated with only the extraversion or agreeableness domains.

However, significant positive correlations were obtained for these scales of social impairment when the experimentally altered version of the NEO PI-R (NEO-X) was used (see Table 3.7). Significant positive correlations were now obtained for IIP Docile/Dependent, IIP Responsible/Over-generous, and PPCA Social Problems. The correlations for the two CCIC scales remained specific to extraversion and agreeableness.

In order to determine if the NEO PI-R extraversion and agreeableness domains were uniquely contributing to the measures of social impairment, a series of hierarchical regression analyses were conducted. Table 3.8 shows the series of analyses with all social impairment measures which obtained significant correlations with the extraversion and/or agreeableness domains of the NEO PI-R with neuroticism and conscientiousness combined as predictors. In the first series of analyses, the NEO PI-R domains of neuroticism and conscientiousness were entered in the first step and the NEO PI-R domains of extraversion and agreeableness were entered in the second step. As expected, in all but one case, neuroticism and conscientiousness were able to describe a significant proportion of variance, ranging from 13\% (CCIC Cooperativeness Problems) to 35\% (IIP Modesty/Self-Effacing). In many cases, the domains of extraversion and agreeableness obtained incremental validity over the domains of neuroticism and conscientiousness in accounting for variance in social impairment. Similarly, when extraversion and agreeableness were entered in the first step, the domains of neuroticism and conscientiousness did explain additional variance in most cases.

Table 3.9 shows two sets of hierarchical regression analyses which examine if the NEO PI-R domains of conscientiousness or neuroticism add incremental validity when they are entered alone as predictors (on those measures which obtained significant correlations with the extraversion and/or agreeableness domains of the NEO PI-R). The first set of analyses examine if conscientiousness was uniquely contributing to these relationships. In the first series of analyses, the NEO PI-R domain of conscientiousness was entered in the first step and NEO PI-R extraversion and agreeableness was entered in the second step. In all but three instances, conscientiousness was able to describe a significant proportion of variance. The domains of extraversion and agreeableness obtained incremental validity over each conscientiousness scale in accounting for variance in social impairment, except when considering BSI Paranoia and K-Axis Social Impairment. When extraversion and agreeableness were entered in the first step, conscientiousness was unable to account for additional variance in four cases (IIP Blunt/Aggressive, IIP Cooperative/Over-conventional, CCIC Interpersonal Problems, and CCIC Cooperativeness Problems). The second set of analyses examine these 
relationships in reference to NEO PI-R neuroticism. In each of the cases where neuroticism was significantly related to a measure of impairment, neuroticism was able to describe a significant proportion of variance, ranging from 11\% (IIP Blunt/Aggressive) to $35 \%$ (IIP Modest/Self-Effacing). When the domains of extraversion and agreeableness were entered in the first step, neuroticism was able to account for significant variance in five cases.

Table 3.10 provides the correlations of the measures of occupational impairment with the domains of the FFM. It is evident from Table 3.10 that all of the measures of occupational impairment were significantly correlated with the NEO PI-R domain of conscientiousness. Significant correlations were obtained with other domains of the FFM but not as frequently or consistently. In order to assess if these other domains were contributing unique variance above and beyond NEO PI-R conscientiousness, a series of hierarchical regression analyses were conducted. Table 3.11 reports the respective variance accounted for by NEO PI-R conscientiousness as well as other domains which were related to occupational impairment. The relationship of NEO PI-R conscientiousness held up well with K-Axis Occupational Impairment, CCIC Reliability Problems, and PPCA Financial Problems despite the significant relationship with other domains. However, in the case of PPCA School Problems, conscientiousness was unable to contribute a significant amount of additional variance when the NEO PI-R openness to experience was entered in the first step. 
Table 3.1

Descriptive Statistics for Respective Instruments

\begin{tabular}{|c|c|c|c|}
\hline \multicolumn{3}{|c|}{ Scale } & Standard Deviation \\
\hline \multicolumn{4}{|l|}{ BSI } \\
\hline & Somatization & 5.82 & 5.38 \\
\hline & Obsessive-Compulsive & 9.63 & 5.84 \\
\hline & Interpersonal Sensitivity & 5.60 & 4.58 \\
\hline & Depression & 8.81 & 6.71 \\
\hline & Anxiety & 7.59 & 5.37 \\
\hline & Hostility & 5.30 & 4.44 \\
\hline & Phobic Anxiety & 3.18 & 3.80 \\
\hline & Paranoia & 5.49 & 4.81 \\
\hline & Psychotic & 6.13 & 5.20 \\
\hline \multicolumn{4}{|c|}{$\mathrm{CCIC}$} \\
\hline & Emotional Problems & 11.46 & 3.15 \\
\hline & Interpersonal Problems & 12.68 & 3.34 \\
\hline & Flexibility Problems & 13.29 & 2.00 \\
\hline & Cooperativeness Problems & 14.90 & 3.27 \\
\hline & Reliability Problems & 10.94 & 2.84 \\
\hline & Relationship Problems & 6.95 & 0.94 \\
\hline \multicolumn{4}{|c|}{ IIP-64 } \\
\hline & Managerial/Autocratic & 15.30 & 4.97 \\
\hline & Competitive/Exploitive & 15.88 & 5.95 \\
\hline & Blunt/Aggressive & 17.07 & 6.70 \\
\hline & Skeptical/Distrustful & 19.57 & 6.92 \\
\hline & Modest/Self-Effacing & 22.23 & 7.72 \\
\hline & Docile/Dependent & 20.09 & 6.24 \\
\hline & Cooperative/Over-conventio & 20.46 & 6.55 \\
\hline & Responsible/Over-generous & 17.47 & 6.05 \\
\hline \multicolumn{4}{|c|}{ K-Axis } \\
\hline & Psychological Functioning & 74.42 & 12.93 \\
\hline & Social Functioning & 81.38 & 13.18 \\
\hline & Occupational Functioning & 85.25 & 13.38 \\
\hline \multicolumn{4}{|c|}{ NEO PI-R } \\
\hline & Neuroticism & 113.21 & 26.11 \\
\hline & Extraversion & 104.62 & 25.50 \\
\hline & Openness & 113.13 & 22.41 \\
\hline & Agreeableness & 114.54 & 17.43 \\
\hline & Conscientiousness & 102.35 & 24.25 \\
\hline \multicolumn{4}{|c|}{ NEO-X } \\
\hline & Neuroticism & 158.19 & 28.40 \\
\hline & Extraversion & 126.69 & 20.79 \\
\hline & Openness & 138.49 & 21.55 \\
\hline & Agreeableness & 143.84 & 16.99 \\
\hline & Conscientiousness & 135.74 & 20.20 \\
\hline
\end{tabular}


Table 3.1 continued

\begin{tabular}{lcl}
\hline PPCA & & \\
Social Problems & 7.09 & 5.07 \\
Appearance Problems & 3.63 & 3.14 \\
Vocational Problems & 3.15 & 4.66 \\
Family Problems & 5.13 & 5.42 \\
School Problems & 2.73 & 3.13 \\
Financial Problems & 4.54 & 3.37 \\
Religious Problems & 2.94 & 3.26 \\
Emotional Problems & 10.00 & 6.08 \\
Sexual Problems & 2.84 & 3.34 \\
Legal Problems & 1.18 & 1.91 \\
Health/Habit Problems & 6.88 & 4.75 \\
Attitude Problems & 2.65 & 2.74 \\
Other Crises & 2.71 & 3.46 \\
\hline
\end{tabular}


Table 3.2

Individual Item Level Correlations with Domains of the NEO PI-R

\begin{tabular}{|c|c|c|c|c|c|c|c|c|c|c|c|}
\hline & \multicolumn{2}{|c|}{ Neuroticism } & \multicolumn{2}{|c|}{ Extraversion } & \multicolumn{2}{|c|}{ Openness } & \multicolumn{2}{|c|}{ Agreeableness } & \multicolumn{2}{|c|}{ Conscientiousness } \\
\hline & & High & Low & High & Low & High & Low & High & Low & High & Low \\
\hline Total item & & 126 & 1 & 15 & 44 & 41 & 1 & 8 & 28 & 3 & 109 \\
\hline & Proportion & & & & & & & & & & \\
\hline BSI & $\begin{array}{c}77 \% \text { of } \\
53 \text { items }\end{array}$ & 40 & 0 & 0 & 4 & 0 & 0 & 0 & 4 & 0 & 29 \\
\hline $\mathrm{CCIC}$ & $\begin{array}{c}36 \% \text { of } \\
127 \text { items }\end{array}$ & 22 & 0 & 4 & 4 & 7 & 0 & 0 & 5 & 2 & 19 \\
\hline IIP & $\begin{array}{l}80 \% \text { of } \\
64 \text { items }\end{array}$ & 30 & 0 & 1 & 26 & 3 & 1 & 7 & 17 & 0 & 26 \\
\hline $\mathrm{K}$-Axis & $\begin{array}{l}100 \% \text { of } \\
3 \text { items }\end{array}$ & 3 & 0 & 0 & 1 & 0 & 0 & 0 & 1 & 0 & 3 \\
\hline PPCA & $\begin{array}{c}41 \% \text { of } \\
208 \text { items }\end{array}$ & 31 & 1 & 10 & 9 & 31 & 0 & 1 & 1 & 1 & 32 \\
\hline
\end{tabular}

$-\quad$ Note. BSI = Brief Symptom Inventory; CCIC = Couples Critical Incidents Checklist; IIP = Inventory of Interpersonal Problems; KAxis $=$ Kennedy Axis V; PPCA = Personal Problems Checklist for Adults. 
Table 3.3

Individual Item Level Correlations with Domains of the Experimentally-Altered Version of the NEO PI-R Domains

\begin{tabular}{|c|c|c|c|c|c|c|c|c|c|c|c|}
\hline & \multicolumn{2}{|c|}{ Neuroticism } & \multicolumn{2}{|c|}{ Extraversion } & \multicolumn{2}{|c|}{ Openness } & \multicolumn{2}{|c|}{ Agreeableness } & \multicolumn{2}{|c|}{ Conscientiousness } \\
\hline & & High & Low & High & Low & High & Low & High & Low & High & Low \\
\hline Total items & & 140 & 0 & 53 & 5 & 93 & 1 & 61 & 9 & 20 & 9 \\
\hline & Proportion & & & & & & & & & & \\
\hline BSI & $\begin{array}{c}83 \% \text { of } \\
53 \text { items }\end{array}$ & 39 & 0 & 7 & 0 & 27 & 0 & 20 & 0 & 0 & 0 \\
\hline $\mathrm{CCIC}$ & $\begin{array}{c}41 \% \text { of } \\
127 \text { items }\end{array}$ & 18 & 0 & 19 & 0 & 12 & 0 & 6 & 6 & 9 & 4 \\
\hline IIP & $\begin{array}{l}77 \% \text { of } \\
64 \text { items }\end{array}$ & 35 & 0 & 13 & 1 & 13 & 0 & 17 & 3 & 7 & 2 \\
\hline $\mathrm{K}$-Axis & $\begin{array}{l}100 \% \text { of } \\
3 \text { items }\end{array}$ & 3 & 0 & 0 & 0 & 3 & 0 & 0 & 0 & 0 & 0 \\
\hline PPCA & $\begin{array}{c}39 \% \text { of } \\
208 \text { items }\end{array}$ & 45 & 0 & 14 & 4 & 38 & 1 & 18 & 0 & 4 & 3 \\
\hline
\end{tabular}

$-\quad$ Note. BSI = Brief Symptom Inventory; CCIC = Couples Critical Incidents Checklist; IIP = Inventory of Interpersonal Problems; KAxis = Kennedy Axis V; PPCA = Personal Problems Checklist for Adults. 
Table 3.4

Correlations of the NEO PI-R Domains with Scales of Affective Impairment

\begin{tabular}{llllll}
\hline & Neuroticism & Extraversion & Openness & Agreeableness & Conscientiousness \\
\hline BSI Anxiety & $.49^{* *}$ & -.15 & .03 & -.05 & $-.26^{*}$ \\
BSI Depression & $.56^{* *}$ & -.23 & .07 & -.07 & $-.31^{*}$ \\
BSI Hostility & $.28^{*}$ & -.12 & -.04 & -.21 & -.20 \\
BSI Interpersonal Sensitivity & $.63^{* *}$ & -.23 & .16 & -.08 & $-.39^{* *}$ \\
BSI Phobia & $.40^{* *}$ & -.18 & -.06 & -.01 & $-.25^{*}$ \\
CCIC Emotional Problems & $.50^{* *}$ & -.06 & .24 & .00 & $-.32^{*}$ \\
K-Axis Psychological Impairment & $.52^{* *}$ & $-.25^{*}$ & -.17 & .10 & $-.33^{* *}$ \\
PPCA Emotional Problems & $.55^{* *}$ & -.14 & $.29^{*}$ & .01 & $-.44^{* *}$ \\
\hline
\end{tabular}

Note. BSI = Brief Symptom Inventory; CCIC = Couples Critical Incidents Checklist; IIP = Inventory of Interpersonal Problems; KAxis $=$ Kennedy Axis V; PPCA $=$ Personal Problems Checklist for Adults.

$* * \mathrm{p}<.01, * \mathrm{p}<.05$ 
Table 3.5

Hierarchical Regression Analyses for Scales of Affective Impairment (with NEO PI-R)

\begin{tabular}{llclc}
\hline & \multicolumn{2}{c}{ Model 1} & \multicolumn{2}{c}{ Model 2} \\
& $\mathrm{R}^{2}$ & $\Delta \mathrm{R}^{2}$ & $\mathrm{R}^{2}$ & $\Delta \mathrm{R}^{2}$ \\
\hline BSI Anxiety & $.09^{*}$ & $.15^{* *}$ & $.24 * *$ & .00 \\
BSI Depression & $.12^{* *}$ & $.19^{* *}$ & $.31^{* *}$ & .00 \\
BSI Interpersonal Sensitivity & $.17^{* *}$ & $.23^{* *}$ & $.40^{* *}$ & .00 \\
BSI Phobia & $.06^{*}$ & $.09^{*}$ & $.15^{* *}$ & .00 \\
CCIC Emotional Problems & $.14^{* *}$ & $.12^{* *}$ & $.26^{* *}$ & .00 \\
K-Axis Psychological Impairment & $.13^{* *}$ & $.19^{* *}$ & $.32^{* *}$ & .00 \\
PPCA Emotional Problems & $.21^{* *}$ & $.11^{* *}$ & $.29 * *$ & .02
\end{tabular}

Note. Model 1: NEO S Conscientiousness entered in the first step, NEO S Neuroticism entered in the second step. Model 2: NEO S Neuroticism entered in the first step, NEO S Conscientiousness entered in the second step.

$* * \mathrm{p}<.01, * \mathrm{p}<.05$ 
Table 3.6

Correlations of the NEO PI-R Domains with Scales of Social Impairment

\begin{tabular}{llllll}
\hline & Neuroticism & Extraversion & Openness & Agreeableness & Conscientiousness \\
\hline BSI Paranoia & $.38^{* *}$ & $-.27^{*}$ & -.05 & $-.34^{* *}$ & $-.36^{* *}$ \\
K-Axis Social Impairment & $.49^{* *}$ & $-.42^{* *}$ & -.02 & $-.31^{*}$ & $-.51^{* *}$ \\
IIP Competitive/Exploitive & $.43^{* *}$ & $-.44^{* *}$ & -.01 & $-.48^{* *}$ & $-.46^{* *}$ \\
IIP Blunt/Aggressive & $.33^{* *}$ & $-.58^{* *}$ & -.03 & $-.34^{* *}$ & $-.34^{* *}$ \\
IIP Skeptical/Distrustful & $.55^{* *}$ & $-.62^{* *}$ & -.04 & $-.34^{* *}$ & $-.50^{* *}$ \\
IIP Modest/Self-Effacing & $.59^{* *}$ & $-.46^{* *}$ & -.09 & -.14 & $-.41^{* *}$ \\
IIP Docile/Dependent & $.54^{* *}$ & -.17 & .13 & .10 & $-.34^{* *}$ \\
IIP Cooperative/Over-conventional & $.39^{* *}$ & .11 & .22 & $.36^{* *}$ & -.06 \\
IIP Responsible/Over-generous & $.26^{*}$ & .01 & .04 & -.07 & $-.29^{* *}$ \\
CCIC Interpersonal Problems & -.19 & $.41^{* *}$ & .10 & $.34^{* *}$ & .16 \\
CCIC Cooperativeness Problems & .13 & -.10 & -.12 & .11 & -.18 \\
PPCA Social Problems & $.49^{* *}$ & -.15 & .11 & & $-.53^{* *}$ \\
\hline
\end{tabular}

$\checkmark \quad$ Note. BSI = Brief Symptom Inventory; CCIC = Couples Critical Incidents Checklist; IIP = Inventory of Interpersonal Problems; KAxis $=$ Kennedy Axis V; PPCA $=$ Personal Problems Checklist for Adults

$* * \mathrm{p}<.01 \quad * \mathrm{p}<.05$ 
Table 3.7

Correlations of the Experimentally-Altered Version of the NEO PI-R Domains with Scales of Social Impairment

\begin{tabular}{|c|c|c|c|c|c|}
\hline & Neuroticism & Extraversion & Openness & Agreeableness & Conscientiousness \\
\hline BSI Paranoia & $.34 * *$ & .18 & $.30 *$ & .19 & .06 \\
\hline K-Axis Social Impairment & $.46^{* *}$ & .10 & $.31 * *$ & .09 & .13 \\
\hline IIP Competitive/Exploitive & $.48 * *$ & .10 & $.32 * *$ & -.03 & -.02 \\
\hline IIP Blunt/Aggressive & $.36 * *$ & -.03 & $.27^{*}$ & .03 & -.02 \\
\hline IIP Skeptical/Distrustful & $.54 * *$ & -.13 & .13 & .06 & -.10 \\
\hline IIP Modest/Self-Effacing & $.57 * *$ & .04 & .17 & $.23 *$ & .04 \\
\hline IIP Docile/Dependent & $.58 * *$ & $.25 *$ & $.26^{*}$ & $.53 * *$ & .11 \\
\hline IIP Cooperative/Over-conventional & $.39 * *$ & $.30 * *$ & $.36 * *$ & $.57 * *$ & $.33 * *$ \\
\hline IIP Responsible/Over-generous & $.31 * *$ & $.52 * *$ & $.32 * *$ & $.25 *$ & .05 \\
\hline CCIC Interpersonal Problems & -.17 & $.46 * *$ & .16 & -.23 & .20 \\
\hline CCIC Cooperativeness Problems & .12 & .01 & .01 & $.50 * *$ & $.36^{* *}$ \\
\hline PPCA Social Problems & $.51 * *$ & .18 & $.38 * *$ & $.32 * *$ & -.03 \\
\hline
\end{tabular}

$\approx$ Note. BSI = Brief Symptom Inventory; CCIC = Couples Critical Incidents Checklist; IIP = Inventory of Interpersonal Problems; KAxis $=$ Kennedy Axis V; PPCA $=$ Personal Problems Checklist for Adults.

$* * \mathrm{p}<.01 \quad * \mathrm{p}<.05$ 
Table 3.8

Hierarchical Regression Analyses for Scales of Social Impairment (with NEO PI-R)

\begin{tabular}{lcccc}
\hline & & Model 1 & \multicolumn{2}{c}{ Model 2} \\
& $\mathrm{R}^{2}$ & $\Delta \mathrm{R}^{2}$ & $\mathrm{R}^{2}$ & $\Delta \mathrm{R}^{2}$ \\
\hline BSI Paranoia & $.17^{* *}$ & .05 & $.11^{*}$ & $.11^{*}$ \\
IIP Competitive Exploitive & $.24^{* *}$ & $.17^{* *}$ & $.29^{* *}$ & $.12^{* *}$ \\
IIP Blunt/Aggressive & $.15^{* *}$ & $.22^{* *}$ & $.33^{* *}$ & .03 \\
IIP Skeptical/Distrustful & $.33^{* *}$ & $.23^{* *}$ & $.43^{* *}$ & $.14^{* *}$ \\
IIP Modest/Self-effacing & $.35^{* *}$ & $.09^{*}$ & $.22^{* *}$ & $.23^{* *}$ \\
IIP Cooperative/Over-conventional & $.21^{* *}$ & $.11^{*}$ & $.13^{*}$ & $.20^{* *}$ \\
CCIC Interpersonal Problems & .04 & $.20^{* *}$ & $.24^{* *}$ & .01 \\
CCIC Cooperativeness Problems & $.13^{*}$ & $.10^{*}$ & $.17^{* *}$ & .06 \\
K-Axis Social Impairment & $.30^{* *}$ & .06 & $.19^{* *}$ & $.17^{* *}$ \\
\hline
\end{tabular}

Note. Model 1: NEO S Conscientiousness and Neuroticism entered in the first step, NEO S Extraversion and Agreeableness entered in the second step. Model 2: NEO S

Extraversion and Agreeableness entered in the first step, NEO S Conscientiousness and Neuroticism entered in the second step.

$* * \mathrm{p}<.01, * \mathrm{p}<.05$ 
Table 3.9

Further Hierarchical Regression Analyses for Scales of Social Impairment (with NEO PI-R)

\begin{tabular}{|c|c|c|c|c|c|c|c|c|}
\hline & \multicolumn{2}{|c|}{ Model 1a } & \multicolumn{2}{|c|}{ Model 2a } & \multicolumn{2}{|c|}{ Model 1b } & \multicolumn{2}{|c|}{ Model 2b } \\
\hline & $\mathrm{R}^{2}$ & $\Delta \mathrm{R}^{2}$ & $\mathrm{R}^{2}$ & $\Delta \mathrm{R}^{2}$ & $\mathrm{R}^{2}$ & $\Delta \mathrm{R}^{2}$ & $\mathrm{R}^{2}$ & $\Delta \mathrm{R}^{2}$ \\
\hline BSI Paranoia & $.14 * *$ & .05 & $.13 *$ & $.06 *$ & $.13 * *$ & .07 & $.11 *$ & .10 \\
\hline IIP Competitive Exploitive & $.19 * *$ & $.18 * *$ & $.31 * *$ & $.06^{*}$ & $.20 * *$ & $.20 * *$ & $.29 * *$ & $.11 * *$ \\
\hline IIP Blunt/Aggressive & $.14 * *$ & $.22 * *$ & $.34 * *$ & .02 & $.11 *$ & $.26^{* *}$ & $.33 * *$ & .03 \\
\hline IIP Skeptical/Distrustful & $.25 * *$ & $.24 * *$ & $.42 * *$ & $.07 * *$ & $.29 * *$ & $.27 * *$ & $.42 * *$ & $.13 * *$ \\
\hline IIP Modest/Self-effacing & $.18 * *$ & $.11^{*}$ & $.21 * *$ & $.07 *$ & $.35 * *$ & $.09 *$ & $.22 * *$ & $.22 * *$ \\
\hline IIP Cooperative/Over-conventional & .00 & $.17 * *$ & $.14^{*}$ & .03 & $.15 * *$ & $.16^{* *}$ & $.19^{*}$ & $.19 * *$ \\
\hline CCIC Interpersonal Problems & .03 & $.22 * *$ & $.24 * *$ & .01 & .04 & $.20 * *$ & $.24 * *$ & .00 \\
\hline CCIC Cooperativeness Problems & .03 & $.14 *$ & $.15^{*}$ & .02 & .01 & $.16^{*}$ & $.17 *$ & .00 \\
\hline K-Axis Social Impairment & $.27 * *$ & .07 & $.20 * *$ & $.14 * *$ & $.22 * *$ & $.11 *$ & $.19 * *$ & $.14 * *$ \\
\hline
\end{tabular}

Note. Model 1a: NEO S Conscientiousness entered in the first step, NEO S Extraversion and Agreeableness entered in the second step. Model 2a: NEO S Extraversion and Agreeableness entered in the first step, NEO S Conscientiousness entered in the second step.

Model 1b: NEO S Neuroticism entered in the first step, NEO S Extraversion and Agreeableness entered in the second step. Model 2b: NEO S Extraversion and Agreeableness entered in the first step, NEO S Neuroticism entered in the second step.

$* * \mathrm{p}<.01, * \mathrm{p}<.05$ 
Table 3.10

Correlations of the NEO PI-R Domains with Scales of Occupational Impairment

\begin{tabular}{llllll}
\hline & Neuroticism & Extraversion & Openness & Agreeableness & Conscientiousness \\
\hline CCIC Reliability Problems & -.21 & $.36^{* *}$ & .02 & .12 & $-.42^{* *}$ \\
K-Axis Occupational Impairment & $.43^{* *}$ & $-.27^{*}$ & .07 & -.18 & $-.57^{* *}$ \\
PPCA Financial Problems & .24 & .15 & $.32^{* *}$ & -.05 & $-.38^{* *}$ \\
PPCA School Problems & .13 & .17 & .20 & -.01 & $-.26^{*}$ \\
\hline
\end{tabular}

A School Problems .13

.17

.20

Note. BSI = Brief Symptom Inventory; CCIC = Couples Critical Incidents Checklist; IIP = Inventory of Interpersonal Problems; KAxis $=$ Kennedy Axis V; PPCA $=$ Personal Problems Checklist for Adults

$* * \mathrm{p}<.01 \quad * \mathrm{p}<.05$ 
Table 3.11

Hierarchical Regression Analyses for Scales of Occupational Impairment (with NEO PI$R)$

\begin{tabular}{lcccc}
\hline & & Model 1 & \multicolumn{2}{c}{ Model 2} \\
& $\mathrm{R}^{2}$ & $\Delta \mathrm{R}^{2}$ & $\mathrm{R}^{2}$ & $\Delta \mathrm{R}^{2}$ \\
\hline CCIC Reliability Problems & $.14^{* *}$ & $.11^{* *}$ & $.19^{* *}$ & $.06^{*}$ \\
K-Axis Occupational Impairment & $.21^{* *}$ & $.13^{* *}$ & $.33^{* *}$ & .01 \\
PPCA Financial Problems & $.13^{* *}$ & $.07^{*}$ & $.12^{* *}$ & $.09^{*}$ \\
PPCA School Problems & .05 & .05 & $.07^{*}$ & .03 \\
\hline
\end{tabular}

Note. Model 1: Other NEO domain entered in the first step, NEO S Conscientiousness. Model 2: NEO S Conscientiousness entered in the first step, other NEO domain entered in the second step. ${ }^{* *} \mathrm{p}<.01, * \mathrm{p}<.05$ 


\section{Section Four: Discussion}

All three $\mathrm{K}$-axis indicators of impairment were associated with at least one domain of the FFM, along with $80 \%$ of the IIP indicators and $77 \%$ of the BSI, consistent with the expectations of McCrae et al. (2005). Only 39\% of the CCIC and $41 \%$ of the PPCA items correlated with the NEO PI-R, increasing to $57 \%$ for the CCIC and $52 \%$ for the PPCA when the experimentally-altered version of the NEO PI-R was considered. The PPCA results are consistent with the coding by McCrae et al. (2005) who indicated that $61 \%$ of the items were classifiable in terms of the FFM. For example, items such as "having a physical handicap," "lacking supervision on the job," "pet dying," and "not receiving child support" would not be predicted to relate to specific domains or facets of personality.

It is unclear why only $57 \%$ of the CCIC items were related in the current study to domains of the FFM. Some of this failure is perhaps attributable to an inadequate range within the current sample of particular problems in living (e.g., few persons endorsed the CCIC problems of "aloof" and "arrogant"). It is also possible that some of the items identified by McCrae et al. (2005) are not in fact personality-related (e.g., "immature"). Nevertheless, a number of the CCIC items do appear to be explicitly related to FFM facets and did obtain an adequate range (e.g., "complains a lot" and "unreliable").

It is not uncommon for researchers to suggest that impairment or maladaptivity associated with the FFM is unidirectional or, more specifically, that it is the profile of high neuroticism, low extraversion, low agreeableness, and low conscientiousness that is associated with maladaptive personality functioning (e.g., Saulsman \& Page, 2004). The current study was the first to administer relatively more comprehensive measures of problems in living that might be associated with both poles of all five domains of the FFM and the results did indicate the existence of a number of problems associated with high agreeableness, high extraversion, and high conscientiousness. Included within the current study were such CCIC items as "overly controlling" (high extraversion), "easily manipulated" (high agreeableness), "overly ambitious" (high conscientiousness), "too regimented" (high conscientiousness) and IIP items "It is hard for me to be firm when I need to be," "I am too easily persuaded by other people," and "I open up to people too much" (all high agreeableness).

The current study, though, found no problems in living associated with low neuroticism or low openness. Indeed, there may be no maladaptive personality traits that concern low levels of neuroticism or low levels of openness (Saulsman \& Page, 2004). However, the findings of the current study may also reflect the possibility that the measures of impairment that were administered failed to in fact provide a fully comprehensive coverage of all problems in living that would be associated with low neuroticism and low openness. For example, excluded from the data collection were the glib charm, fearlessness, and low anxiousness of psychopathy that are theoretically and empirically related to low neuroticism (Miller \& Lynam, 2003) and presumably contribute to problems in living for psychopathic persons with these traits (e.g., low anxiousness and fearlessness contributing to a failure to adequately anticipate risks and dangers; Hare, 2003). Similarly, with the exception of the CCIC, excluded from the data collection were problems in living that might be associated with low openness to feelings and ideas, such as alexithymia (Taylor \& Bagby, 2004) and prejudicial closedmindedness (Bell, 2006; Flynn, 2005). 
The current study also found that impairments were disproportionately spread across the poles of the five domains, with relatively more problems in living identified with low conscientiousness, low agreeableness, and low extraversion, as well as with high neuroticism and high openness. This differential distribution of problems in living is in fact largely consistent with the distribution of maladaptivity within the language itself. Coker, Samuel, and Widiger (2002) obtained social desirability ratings for all 1,710 of the trait terms included within the Big Five lexicon of English language trait terms (Goldberg, 1982). They empirically analyzed the relationship of each term's social desirability to each term's location within the Big Five lexicon (as being either high or low on each of the Big Five domains). The results indicated that $60 \%$ of the trait terms describing high neuroticism were socially undesirable, $89 \%$ of the trait terms describing low extraversion, $94 \%$ of the trait terms describing low openness, $97 \%$ of the trait terms describing low agreeableness, and $97 \%$ of the trait terms describing low conscientiousness. These results were consistent with those obtained for the opposite poles (i.e., only $8 \%, 42 \%, 26 \%, 14 \%$, and $20 \%$, of the trait terms describing low neuroticism, high extraversion, high openness, high agreeableness, and high conscientiousness were rated as socially undesirable, respectfully). In sum, for the domains of neuroticism, extraversion, agreeableness, and conscientiousness, the distribution of the problems in living associated with the respective poles of these domains obtained in the current study are consistent with the social desirability of the language describing these domains. This should not, of course, be too surprising, if the language does provide an accurate description of actual personality functioning (Saucier \& Goldberg, 1996).

A notable exception was the distribution obtained for openness. Coker et al. (2002) indicated that only $26 \%$ of the trait terms within the language describing high openness to experience, compared to $94 \%$ describing low openness to experience, were considered to be socially undesirable traits, whereas, in the current study, all of the problems in living were related to high openness to experience rather than low openness to experience. On the other hand, the findings of the current study are consistent with prior personality disorder research. Openness to experience is typically relatively weakly associated with personality disorder symptomatology but when a relationship is found, it is typically indicating maladaptivity associated with high openness to experience rather than low openness to experience (Saulsman \& Page, 2004). For example, schizotypal symptomatology is most often associated with high levels of openness to fantasy and openness to ideas (Haigler \& Widiger, 2001). Nevertheless, studies of the language itself might suggest that the existing personality disorder nomenclature is perhaps neglecting to recognize maladaptive personality traits related to low openness to experience. Examples of English language trait terms from low openness that are considered to be undesirable include, "prejudiced," "closed-minded," "dogmatic," and "unimaginative." While not represented in the current diagnostic system, individuals high in the traits of closedmindedness and prejudice similarly might experience associated problems in living. Assessment of Maladaptive Variants

It must be emphasized, however, that both the English language and the current study do suggest the presence of problems in living associated with high extraversion, high agreeableness, and high conscientiousness. In fact, fully $42 \%$ of the trait terms describing high extraversion were classified by Coker et al. (2002) as socially undesirable 
(e.g., "blustery," "showy," "exaggerative," and "long-winded"). Their results also were consistent with an independent, unpublished coding of social desirability by Norman (1967). His coding of the same set of 1,710 trait terms identified by Goldberg (1982) within the English language, suggested that $33 \%$ of the terms describing high extraversion were socially undesirable. It is the case that there are fewer of these terms than are present for low extraversion, but when assessing for maladaptive variants of the FFM, they should perhaps not be shortchanged. The domain of openness itself consists of fewer trait terms than the other four domains, but if it is determined that openness should be included within an assessment of the FFM, it should receive as much fidelity and power as the assessment of any other domain. Just as many items are included within the NEO PI-R for the assessment of FFM openness as there are items for the assessment of FFM extraversion (Costa \& McCrae, 1992). Similarly, even though there are fewer trait terms in the language for maladaptive agreeableness than for maladaptive antagonism, maladaptive agreeableness might be as important to assess as reliably, validly, and comprehensively within clinical populations as maladaptive antagonism.

Only $2 \%$ of the NEO PI-R low neuroticism items, $10 \%$ of the high extraversion, $12 \%$ of the high openness, $17 \%$ of the high agreeableness, and $10 \%$ of the high conscientiousness items refer to maladaptive personality functioning (Haigler \& Widiger, 2001). This distribution of items within the NEO PI-R parallels the distribution of trait terms within the English language and the distribution of problems in living obtained in the current study (with the exception of openness). The current study found that when the existing NEO PI-R items were altered to reverse the differential distribution of maladaptive variants of the respective traits (e.g., $90 \%$ of the high extraversion, $83 \%$ of the high agreeableness, and $90 \%$ of the high conscientiousness items were describing maladaptive or socially undesirable traits in the experimentally-altered version of the NEO PI-R), the proportional representation of problems in living were similarly reversed (see Table 4). In fact, the results then suggested that there were more problems in living associated with high extraversion rather than with low extraversion, high agreeableness rather than with low agreeableness, and high conscientiousness rather than with low conscientiousness. If one collapsed across the two versions of the NEO PI-R, the results would even indicate more problems with living associated with high extraversion (68 significant correlations) than with low extraversion (49 significant correlations). In sum, an empirical study of the relationship of the domains of the FFM with personality disorder symptomatology and problems in living will be quite sensitive to the distribution of items within the instrument being used to assess the FFM, and if adequate consideration is not provided to the assessment of maladaptive extraversion, maladaptive agreeableness, and maladaptive conscientiousness, it is quite possible that inaccurate and misleading findings will be obtained.

Definition of Personality Disorder

Provided in DSM-IV-TR is a definition of personality traits as "enduring patterns of perceiving, relating to, and thinking about the environment and oneself that are exhibited in a wide range of social and personal contexts" (APA, 2000, p. 686). It is "only when personality traits are inflexible and maladaptive and cause significant functional impairment or subjective distress do they constitute Personality Disorder" (APA, 2000, p. 686). It is stated more specifically within the general diagnostic criteria for a personality disorder that personality disorders involve "clinically significant distress 
or impairment in social, occupational, or other important areas of functioning" (APA, 2000, p. 689).

The results of the current study support the hypothesis that the structure of the FFM may be relatively well organized with respect to this definition of personality disorder. NEO PI-R neuroticism was significantly related to various forms of affective impairment, including anxiety, depression, hostility, sensitivity, and emotional problems. Extraversion, agreeableness, and openness were not associated with any measure of distress. Conscientiousness was associated with most of the measures of distress. However, conscientiousness was unable to account for any variance in distress above and beyond neuroticism, which suggests that neuroticism has a sole and unique relationship with the measures of affective impairment.

Similarly, as expected, all four measures of occupational impairment were significantly related to low conscientiousness. Correlations were obtained for three of the other four domains of the FFM (i.e., neuroticism, extraversion, and openness) and some unique variance in financial problems and reliability problems were accounted for by the other four domains. However, the relationships with the other four domains were not as frequent or consistent as those obtained for conscientiousness.

The findings for social impairment were not as specific as those obtained for distress or occupational impairment. Extraversion and agreeableness were significantly related to all of the measures of social impairment when both the NEO PI-R and the experimentally-altered version of the NEO PI-R (Haigler \& Widiger, 2001) were used. Nevertheless, significant correlations of social impairment were also obtained with neuroticism and conscientiousness. Much of the variance in social impairment that was associated with conscientiousness was accounted for by extraversion and/or agreeableness, but there remained an appreciable variance that was still explained by neuroticism. For example, neuroticism accounted for $14 \%$ of the variance in the K-Axis social impairment after the variance explained by extraversion and agreeableness was removed.

Extraversion and agreeableness do appear to be the predominant domains for understanding social problems in living. Finding that neuroticism provides a significant and unique contribution as well is consistent with existing research. Neuroticism, as a disposition to respond poorly to environmental stress and to experience even minor frustrations as hopelessly overwhelming (Costa \& McCrae, 1992) would, not surprisingly, provide a contribution to the occurrence of a variety of negative life outcomes. Beyond its robust relationship to various forms of psychopathology (Malouff, Thorsteinsson, \& Schutte, 2005), neuroticism is associated with the occurrence of a variety of physical illnesses (Smith \& MacKenzie, 2006; Suls \& Bunde, 2005), lower subjective well-being (Steel, Schmidt, \& Schultz, 2008), greater unprotected sexual activity (Hoyle, Fejfar, \& Miller, 2000), lower happiness (DeNeve, \& Cooper, 1998), higher dependency (Bornstein \& Cecero, 2000), higher extrinsic religiosity (Saroglou, 2002), higher criminal arrest (Huo-Liang, 2006) and, more specific to the focus of this study, dissatisfaction with, conflict within, and dissolution of relationships (Ozer \& Benet-Martinez, 2006).

The contribution of neuroticism to these negative life outcomes can be in part a direct effect of the high levels of affective distress. For example, with respect to lowered physical health, neuroticism could provide a direct effect through altered autonomic 
regulation of the cardiovascular system, immune suppression, and increased inflammation associated with higher levels of negative affectivity (Smith \& MacKenzie, 2006; Suls \& Bunde, 2005). Nevertheless, there could also be an indirect effect, through poorer health habits, increased exposure to daily stressors and other life difficulties (Smith \& MacKenzie, 2006; Suls \& Bunde, 2005). The same can occur for the contribution of neuroticism to impairments in social relationships. Neuroticism can contribute both diathesis and stress (Caspi, Roberts, \& Shiner, 2005). High levels of neuroticism can result in difficulties in experiencing and responding to problematic, stressful interpersonal relationships, but one's frequent expressions of upset, worry, and vulnerability can also produce negative reactions from others, thus reinforcing and increasing the original distress (i.e., personality as causing stress). There is empirical support, for instance, for a relationship of neuroticism to the presence and experience of lower levels of social support (Kendler, Gardner, \& Prescott, 2006).

Nevertheless, the predominant finding of the current study is that the FFM is perhaps well suited as a dimensional model of personality disorder in that four of its five domains do appear to have relatively specific implications with respect to the three components of distress, social impairment, and occupational impairment that provide the primary basis for identifying when personality traits constitute a personality disorder (APA, 2000). This is perhaps in contrast to the existing diagnostic nomenclature, wherein the personality disorders do not appear to have as specific implications for distress, social impairment, or occupational impairment.

One could perhaps make some predictions of relatively specific associations of the DSM-IV-TR personality disorders with the three identified components of personality disorder (e.g., dependent and narcissistic personality disorders with social impairment, antisocial and obsessive-compulsive with occupational impairments, and borderline with affective distress). A number of studies have been conducted to indicate a close relationship of personality disorders to interpersonal problems in living, and this research has suggested particularly strong relationships for the dependent, narcissistic, antisocial, schizoid, paranoid, and avoidant personality disorders (e.g., Hilsenroth, Menaker, Peters, \& Pincus, 2007; Trobst, Ayearst, \& Salekin, 2004; Vittengl, Clark, \& Barrett, 2003; Wiggins \& Pincus, 1989). There is also research on the relationship of personality disorders to global dysfunction (e.g., Johnson et al., 2000, 2005; Hong et al., 2005). Smith and Benjamin (2002) concluded that personality disorders are related to dysfunction "in nearly every realm of concern to health care providers" (p. 135). The Collaborative Longitudinal Personality Disorders Study (CLPS) has considered separately social and occupational functioning, but the respective studies have been confined to just four personality disorders (Skodol et al., 2002, 2005). There has, as yet, been no study to indicate whether the 10 personality disorders of DSM-IV-TR have relatively specific implications with respect to social dysfunction, occupational dysfunction, and affective distress. It might be of interest for future research to directly compare the alternative nomenclatures of personality disorder, the DSM-IV-TR and the FFM, with respect to the specificity of their relationships with affective distress, social impairment, and occupational impairment.

Openness to Experience

It was also apparent from the current study that openness to experience contributed very little to distress, social impairment, or occupational impairment. 
Openness to experience obtained only one significant correlation with a measure of distress (PPCA emotional problems) and with no measures of social impairment (when the NEO PI-R was used) and with only one measure of occupational impairment (PPCA financial problems). Openness to experience did appear to relate to quite a number of problems in living when analyses were conducted at the level of individual items, but the bulk of these findings occurred for items from the PPCA, and the two significant correlations that were obtained with respect to scales were from the PPCA. Neither of these findings was predicted to occur, and they may not replicate in future research.

This finding for openness is consistent with prior research that has obtained a relatively weak relationship of personality disorder symptomatology with this domain of the FFM (O'Connor, 2005; Saulsman \& Page, 2004). It is perhaps conceivable that an adequate dimensional model of personality disorder that is coordinated with general personality structure could be confined to just four of the five domains of the FFM, excluding openness (Widiger \& Simonsen, 2005). A four-factor dimensional model of personality disorder might then exclude though important individual differences in maladaptive personality functioning, including cognitive and perceptual aberrations, absorption, and eccentricity at the high end of openness and alexithymia, stubbornness, and closed-mindedness at the low end (Widiger \& Simonsen, 2005). A possible reason that a fifth factor often fails to appear in factor analytic personality disorder research is that the frequency and number of symptoms of maladaptive openness are not sufficiently large enough to carry an independent factor, relative to the other four. This was demonstrated empirically by Tackett, Silberschmidt, Krueger, and Sponheim (in press), who obtained a fifth factor of personality disorder symptomatology (titled peculiarity) when sufficient representation of cognitive-perceptual aberrations were included. This factor has aligned well with openness in prior FFM personality disorder research (e.g., Camisa et al., 2005; Haigler \& Widiger, 2001; Ross, Lutz, \& Bailley, 2002; Wiggins \& Pincus, 1989).

In sum, perhaps one of the reasons that none of the measures of impairment included in the current study correlated with openness is that the problems in living primarily associated with openness are not currently included within the definition of personality disorder, being confined to distress and social and occupational impairment (e.g., the BSI does include such cognitive impairments as "psychoticism"). Some alternative definitions of personality disorder are more extensive than provided by the DSM-IV-TR (APA, 2000). For example, in the conceptualization of personality disorder offered by Millon et al. (1996), dysfunction is assessed across a wide range of personality components, including cognition, along with interpersonal conduct, self-image, object representations, temperament, morphologic organization, regulatory mechanisms, and expressive acts. If the definition of personality disorder provided in DSM-IV-TR was revised to include cognitive impairments, along with social impairments, occupational impairments, and distress, it is perhaps likely that the potential relevance of openness might become more apparent.

Cognition is in fact included within the DSM-IV description of what constitutes personality functioning (along with affectivity, interpersonal functioning, and impulse control). The DSM-IV-TR definition of personality functioning specifies four areas of functioning (APA, 2000), that are in fact nicely organized with respect to the five domains of the FFM. The four areas are affect (i.e., neuroticism), interpersonal 
relationships (i.e., extraversion and agreeableness), impulse control (i.e., conscientiousness), and cognition (i.e., openness to experience). In contrast, the impairment requirement of "clinically significant distress or impairment in social, occupational, or other important areas of functioning" (APA, 2000, p. 689) makes no reference to an impairment with respect to cognition.

Treatment Implications

An advantage of having a nomenclature with relatively specific implications for areas of dysfunction is the potential that these problems in living will also have relatively specific treatment implications. It is perhaps telling that it has been over ten years since the American Psychiatric Association has been publishing practice guidelines for the diagnostic categories of DSM-IV-TR and, as yet, treatment guidelines have been developed for only one of the 10 personality disorder diagnostic categories (i.e., APA, 2001). The reason might be straightforward; there have been no adequate empirical studies on the treatment of (for instance) the avoidant, schizoid, paranoid, histrionic, narcissistic, obsessive-compulsive, avoidant, or dependent personality disorders. There is very little that can be said empirically regarding their treatment.

It would be difficult to even find researchers attempting to develop manualized treatment programs for the purpose of developing and testing empirically-based treatments for the dependent, narcissistic, schizoid, obsessive-compulsive, histrionic, and other personality disorders. One reason might be that the DSM-IV-TR personality disorders are generally not well suited for specific and explicit treatment manuals because each disorder involves a complex constellation of an array of maladaptive personality traits (Clark, 2007; Lynam \& Widiger, 2001; Widiger \& Trull, 2007). The diagnostic categories consist of diverse and complex arrays of maladaptive personality traits that do not lend themselves well to the development of specific treatment guidelines (Verheul, 2005).

The factor analytic development of the FFM could provide a more conceptually (as well as empirically) coherent structure. Extraversion and agreeableness could be primarily relevant to the social, interpersonal dysfunction, an area of functioning that is relevant to relationship quality both outside and within the therapy office (Pincus \& Gurtman, 2006). Interpersonal models of therapy, marital-family therapy, and group therapy might be confined largely to these two domains, or at least they would have the most specific and explicit implications for extraversion and agreeableness (Horowitz \& Wilson, 2005; Markowitz, 2005; Sholevar, 2005). In contrast, neuroticism provides information with respect to the distress, or more precisely mood, anxiety, and emotional dyscontrol, often targets for pharmacologic interventions (as well as cognitive interventions). There are very clear pharmacologic implications for mood and anxiety dysregulation and emotional instability (Soloff, 2005), but little to none for maladaptive antagonism or introversion, the interpersonal domains of the FFM (Wiggins \& Pincus, 2002). As noted previously, maladaptively high openness implies cognitive-perceptual aberrations, which again has pharmacologic implications that would be quite different from those of neuroticism (Soloff, 2005). The domain of conscientiousness is, in contrast to agreeableness and extraversion, the domain of most specific relevance to occupational dysfunction, or impairments concerning work and career. Maladaptively high levels involve workaholism, perfectionism and compulsivity, low levels involve laxness, negligence, and irresponsibility. There are even specific pharmacologic treatment 
implications for low conscientiousness (e.g., attention-deficit and hyperactivity; Nigg et al., 2002; Van der Oord, Prins, Oosterlaan, \& Emmelkamp, 2007) although, as yet, none for maladaptively high conscientiousness. Perhaps there never will be pharmacological treatment implications for high conscientiousness, but the point is that the structure of the FFM might be commensurate with relatively more specific treatment implications than the existing diagnostic categories. It would be of interest to explore in future research whether the FFM does indeed result in more specific treatment implications than the existing diagnostic categories.

\section{Characteristic Maladaptations and Adaptations}

The findings of the current study are also consistent with the growing interest in separating the assessment of personality disorder from the assessment of personality dysfunction (Clark, 2007; Parker et al., 2002, 2004). As expressed by members of the DSM-V Personality Disorders Work Group, "we see the concept of a diagnosable PD as involving the combination of personality traits and a separate but complementary evaluation of personality dysfunction" (Krueger et al., 2008, p. 93). This approach would recognize that dysfunction can at times be situation specific and may not be inherent to a particular constellation of personality traits (Widiger \& Costa, 1994). Some particular constellation of personality traits may be associated with functional strengths as well as impairments. The separation of the assessment of traits and dysfunction is also consistent with the FFM procedure for the diagnosis of a personality disorder, wherein the first step is to obtain comprehensive assessment of the person in terms of the FFM domains and facets and the second step is to identify the social and occupational impairments and distress that are associated with any particular trait elevation (Widiger, Costa \& McCrae, 2002).

An issue, however, that warrants further consideration is the extent to which traits and problems in living can in fact be truly separated, conceptually and methodologically. In what is at times referred to as the Five Factor Theory (McCrae \& Costa, 2003), the NEO PI-R assesses biological dispositions to engage in particular behaviors in reaction to environmental situations and conditions. The actual behaviors are referred to as characteristic adaptations (i.e., patterns of thoughts, feelings, and behaviors) when they are, for the most part, functional, and characteristic maladaptations when they are inconsistent with or problematic for functioning within predominant environmental contexts.

There is empirical support for suggesting that the NEO PI-R is assessing underlying biological dispositions (Munafo, Clark, \& Flint, 2005; Schinka, Busch, \& Robichaux-Keene, 2004; Sen, Burmeister, \& Ghosh, 2004; Yamagata et al., 2006). However, it is also clearly assessing as well the personality traits of the person, or the characteristic adaptations (particularly for low neuroticism, high extraversion, high openness, high agreeableness, and high conscientiousness) and the characteristic maladaptations (particularly for high neuroticism, low extraversion, low openness, low agreeableness, and low conscientiousness). A NEO PI-R item, "I'm something of a "workaholic"" (Costa \& McCrae, 1992, p. 73) is assessing the biological disposition that underlies the domain of conscientiousness (Yamagata et al., 2006) as well as the characteristic maladaption of spending too much time in work-related related behaviors to the detriment of other areas of life. Similarly, the NEO PI-R item, "I work hard to accomplish my goals" (Costa \& McCrae, 1992, p. 73) is again contributing to the 
assessment of the biological disposition that underlies conscientiousness (Yamagata et al., 2006), as well as the characteristic adaptation of working toward the achievement of important life goals. In sum, it is not at all clear how the assessments of the traits and the dysfunctions or impairments can in fact be truly separated.

The separation of the assessment of traits and dysfunction is perhaps better understood as a distinction between broad personality traits and more specific behavioral acts, both of which exist within a common hierarchical structure (Markon, Krueger, \& Watson, 2005). A criticism of the DSM-IV-TR diagnostic criterion sets (as well as past editions of this diagnostic manual) is that they constitute a mixture of traits and behaviors (Clark, 1992; Hare, 2003; Shea, 1992). It is evident that diagnostic criteria that refer to broad personality traits perform differently in research than items that concern specific behaviors. One of the findings of the CLPS project is that the diagnostic criteria that refer to broad personality traits tend to have higher levels of temporal stability than criteria that are more behaviorally specific (Grilo et al., 2007; McGlashan et al., 2005; Warner et al., 2004; Zanarini et al., 2007). Nevertheless, it is also apparent that any assessment of a broad personality trait, such as impulsivity, would require the assessment of behaviors (e.g., reckless driving, binge eating, substance abuse, or promiscuous sexual acts; APA, 2000) as specific as the behaviorally specific diagnostic criteria, such as recurrent suicidal behavior. It is not that the assessment of traits is separate from the assessment of behaviors; it is just that the assessment of traits considers a broader array of behaviors.

In sum, the distinction between the assessment of traits and dysfunctions (or characteristic maladaptions) might be more fruitfully considered to be primarily a distinction between the assessment of traits and behaviors. Any particular personality trait (e.g., conscientiousness) can be assessed through a wide variety of specific behaviors (e.g., paying debts promptly, adhering to strict ethical principles, working hard to accomplish goals, and finishing projects once they are started; Costa \& McCrae, 1992). Some of these behaviors will be functional (working hard to achieve goals), whereas others will be dysfunctional (working so hard that family life suffers). The assessment of the traits is not actually separate from the behaviors, but the behaviors can themselves be distinguished with respect to whether they are adaptive or maladaptive.

\section{Limitations}

A limitation of the current study is the reliance on a single methodology, selfreport. There is considerable empirical support for the validity of self-report measures of personality and personality disorder (Widiger \& Boyd, in press) but it would be useful to expand the data collection to include additional methods of assessment, including semistructured interviews and informant reports. It is possible, for instance, that semistructured interviewers and close, personal colleagues of the person will identify additional dysfunctions that are not as readily apparent to the person. It is generally found that informant reports result in an increase in the amount of personality disorder symptomatology that is identified (Klonsky, Oltmanns, \& Turkheimer, 2002; Ready \& Clark, 2002). They may also provide additional examples of personality-related problems in living.

The lack of a more evenly balanced sample of males and females could also be a limiting factor of the current study. The gender ratio of the current sample favored females by a 3 to 1 ratio. This ratio is consistent with the gender proportions frequently found in outpatient psychotherapy clinics. Nevertheless, there are considerable 
differences in gender ratio for some of the personality disorders, many of which occur more frequently in men, such as the antisocial, narcissistic, and obsessive-compulsive (APA, 2000; Morey, Alexander, \& Boggs, 2005). There are also closely related sex differences with respect to the domains and facets of the FFM (Lynam \& Widiger, 2007). There was no indication in the current study that impairments that are more common to these personality disorders were not adequately represented (e.g., impairments related to high antagonism), but it would be useful for future research to obtain a more balanced representation of the sexes.

It would also be useful for future research to consider additional measures of impairment and dysfunction. The current study administered commonly used measures of impairment that were developed to provide reasonably comprehensive assessments of problems in living for psychiatric patients, such as the Personal Problems Checklist for Adults (Schinka, 1985), the Inventory of Interpersonal Problems (Horowitz et al., 2000), and the Brief Symptom Inventory (Derogatis, 2004). However, additional measures should be considered as well in future research, particularly those that might provide a better representation of impairments related to low openness to experience and low neuroticism.

Conclusions

In sum, the results of the current study suggest that problems in living are associated with at least eight of the ten poles of the FFM. The results do support the assertion that the five domains and the ten poles of the five domains, do not have equal implications for maladaptivity as impairments were disproportionately distributed in a manner that was generally consistent with the distribution of maladaptivity within the language, with the exception of openness to experience. However, the findings of the current study also indicated that the assessment of these problems in living is affected considerably by the representation of maladaptive personality traits within the assessment instrument. Results of the current study also support the hypothesis that the relationship of the FFM domains to problems in living parallels the definition of personality disorder as provided in the APA (2000) diagnostic manual, concerning social impairment, occupational impairment, and personal distress, but I also suggest that the definition of personality disorder might be fruitfully revised to include impairments of cognition. It will be useful for future research to examine level of impairment as assessed by additional methods of assessment and additional measures of personality dysfunction. 
Appendix A: Correlations of the Experimentally-Altered Version of the NEO PI-R Domains with Scales of Affective Impairment

\begin{tabular}{llllll}
\hline & Neuroticism & Extraversion & Openness & Agreeableness & Conscientiousness \\
\hline BSI Anxiety & $.51^{* *}$ & $.26^{*}$ & $.32^{* *}$ & $.28^{*}$ & .12 \\
BSI Depression & $.54^{* *}$ & .10 & $.34^{* *}$ & $.27^{*}$ & .12 \\
BSI Hostility & $.27^{*}$ & $.23^{*}$ & .20 & .08 & .06 \\
BSI Interpersonal Sensitivity & $.59^{* *}$ & .18 & $.38^{* *}$ & $.36^{* *}$ & .10 \\
BSI Phobia & $.35^{* *}$ & .17 & $.24^{*}$ & $.35^{* *}$ & .13 \\
CCIC Emotional Problems & $.44^{* *}$ & .22 & $.32^{*}$ & .15 & -.07 \\
K-Axis Psychological Impairment & $.52^{* *}$ & .14 & $.36^{*}$ & .19 & -.02 \\
PPCA Emotional Problems & $.57^{* *}$ & .17 & $.46^{* *}$ & $.25^{*}$ & .10 \\
\hline
\end{tabular}

Note. BSI = Brief Symptom Inventory; CCIC = Couples Critical Incidents Checklist; IIP = Inventory of Interpersonal Problems; KAxis $=$ Kennedy Axis V; PPCA = Personal Problems Checklist for Adults.

$\tilde{u}^{* *} \mathrm{p}<.01, * \mathrm{p}<.05$ 
Appendix B: Hierarchical Regression Analyses for Scales of Social Impairment (with Experimental NEO)

\begin{tabular}{llclc}
\hline & & Model 1 & \multicolumn{2}{c}{ Model 2} \\
& $\mathrm{R}^{2}$ & $\Delta \mathrm{R}^{2}$ & $\mathrm{R}^{2}$ & $\Delta \mathrm{R}^{2}$ \\
\hline CCIC Cooperativeness Problems & $.15^{*}$ & $.15^{*}$ & $.27^{* *}$ & .02 \\
CCIC Interpersonal Problems & .07 & $.36^{* *}$ & $.34^{* *}$ & $.09^{*}$ \\
IIP Modest/Self-Effacing & $.30^{* *}$ & .01 & .06 & $.25^{* *}$ \\
IIP Docile/Dependent & $.35^{* *}$ & $.12^{* *}$ & $.29^{* *}$ & $.18^{* *}$ \\
IIP Cooperative/Over-conventional & $.25^{* *}$ & $.16^{* *}$ & $.37^{* *}$ & .04 \\
IIP Responsible/Over-generous & .08 & $.24^{* *}$ & $.26^{* *}$ & .06 \\
PPCA Social Problems & $.24^{* *}$ & .04 & $.10^{*}$ & $.18^{* *}$ \\
\hline
\end{tabular}

Note. Model 1: X NEO Conscientiousness and Neuroticism entered in the first step, $\mathrm{X}$ NEO Extraversion and Agreeableness entered in the second step. Model 2: X NEO Extraversion and Agreeableness entered in the first step, X NEO Conscientiousness and Neuroticism entered in the second step. ${ }^{* *} \mathrm{p}<.01,{ }^{*} \mathrm{p}<.05$ 
Appendix C: Correlations of the Experimentally-Altered Version of the NEO PI-R Domains with Scales of Occupational Impairment

\begin{tabular}{llllll}
\hline & Neuroticism & Extraversion & Openness & Agreeableness & Conscientiousness \\
\hline CCIC Reliability Problems & -.19 & -.02 & -.06 & .03 & $-.36^{* *}$ \\
K-Axis Occupational Impairment & $.50^{* *}$ & $.24^{*}$ & $.31^{*}$ & $.24^{*}$ & .10 \\
PPCA Financial Problems & $.31^{*}$ & $.36^{* *}$ & $.41^{* *}$ & .09 & -.13 \\
PPCA School Problems & .14 & $.25^{*}$ & $.26^{*}$ & .10 & .02 \\
\hline
\end{tabular}

Note. $\mathrm{CCIC}=$ Couples Critical Incidents Checklist; IIP = Inventory of Interpersonal Problems; K-Axis = Kennedy Axis V; PPCA =

Personal Problems Checklist for Adults. ${ }^{* *} \mathrm{p}<.01,{ }^{*} \mathrm{p}<.05$ 
References

American Psychiatric Association. (2000). Diagnostic and statistical manual of mental disorders-Text Revision. (4 ${ }^{\text {th }}$ ed., text revision). Washington, D.C.: Author.

American Psychiatric Association. (2001). Practice Guidelines for the Treatment of Patients with Borderline Personality Disorder. Washington, D.C.: Author.

Artistico, D., Baldassarri, F., Lauriola, M., \& Laicardi, C. (2000). Dimensions of healthrelated dispositions in elderly people: Relationships with health behaviour and personality traits. European Journal of Personality, 14, 533-552.

Ashton, M. C. \& Lee, K. (2001). A theoretical basis for the major dimensions of personality. European Journal of Personality, 15, 327-353.

Bagby, R.M., \& Farvolden, P. (2004). The Personality Diagnostic Questionnaire-4 (PDQ4). In M.J., Hilsenroth, D.L. Segal, \& M. Hersen (Eds.). Comprehensive handbook of psychological assessment, Volume 2. Personality assessment (pp. 122-133). NY: John Wiley.

Ball, S. A. (2001). Reconceptualizing personality disorder categories using personality trait dimensions: Introduction to special section. Journal of Personality, 69, 147153.

Bell, C.C. (2006). Reservations and hopes. In T.A. Widiger, E. Simonsen, P.J. Sirovatka, \& D.A. Regier (Eds.), Dimensional models of personality disorders. Refining the research agenda for DSM-V (pp. 195-198). Washington, DC: American Psychiatric Association.

Bornstein, R. F., \& Cecero, J. J. (2000). Deconstructing dependency in a five-factor world: A meta-analytic review. Journal of Personality Assessment, 74, 324-343.

Camisa, K. M., Bockbrader, M. A., Lysaker, P., Rae, L. L., Brenner, C. A., \& O'Donnell, B. F. (2005). Personality traits in schizophrenia and related personality disorders. Psychiatry Research, 133, 23-33.

Caspi, A., Roberts, B. W., \& Shiner, R. L. (2005). Personality development: Stability and change. Annual Review of Psychology, 56, 453-484.

Clark, L. A. (1992). Resolving taxonomic issues in personality disorders: The value of large-scale analyses of symptom data. Journal of Personality Disorders, 6, 360376.

Clark, L. A. (1993). Manual for the Schedule for Nonadaptive and Adaptive Personality. Minneapolis, MN: University of Minnesota Press.

Clark, L. A. (2007). Assessment and diagnosis of personality disorder: Perennial issues and an emerging reconceptualization. Annual Review of Psychology, 57, 277-257.

Clark, L. A. \& Livesley, W. J. (2002). Two approaches to identifying the dimensions of personality disorder: Convergence on the five-factor model. In T. A. Widiger \& P. T. Costa (Eds.), Personality disorders and the five-factor model of personality ( ${ }^{\text {nd }}$ ed., pp. 161-176).

Clark, L. A., Simms, L. J., Wu, K. D., \& Casillas, A. (2007). Manual for the Schedule for Nonadaptive and Adaptive Personality (SNAP-2). Minneapolis, MN: University of Minnesota Press.

Coker, L. A., Samuel, D. B. \& Widiger, T. A. (2002). Maladaptive personality functioning within the Big Five and the five-factor model. Journal of Personality Disorders, 16, 385-401.

Costa, P. T., Jr. \& McCrae, R. R. (1992). The NEO PI-R professional manual. Odessa, 
FL: Psychological Assessment Resources.

Costa, P., \& McCrae, R. R. (1995). Domains and facets: Hierarchical personality assessment using the Revised NEO Personality Inventory. Journal of Personality Assessment, 64, 21-50.

Costa, P. T., Jr., McCrae, R. R. \& Siegler, I. C. (1999). Continuity and change over the adult life cycle: Personality and personality disorders. In C. R. Cloninger's (Ed.), Personality and psychopathology (pp. 129-154). Washington, D.C.: American Psychiatric Association.

DeNeve, K., \& Cooper, H. (1998). The happy personality: A meta-analysis of 137 personality traits and subjective well-being. Psychological Bulletin, 124, 197229.

Derogatis, L. R. (2004). SCL-90-R administration, scoring and procedures manual II. Towson, MD: Clinical Psychometric Research.

Digman, J. M. (1990). Personality structure: Emergence of the five-factor model. Annual Review of Psychology, 41, 417-470.

Farrell, A. D. \& McCullough-Vaillant, L. (1996). Computerized Assessment System for Psychotherapy Evaluation and Research (CASPER): Development and current status. In M. J. Miller, K. W. Hammond, \& M. M. Hile (Eds.), Mental health computing (pp. 34-53). New York: Springer.

Flynn, F. J. (2005). Having an open mind: The impact of openness to experience on interracial attitudes and impression formation. Journal of Personality and Social Psychology, 88, 816-826.

Goldberg, L. R. (1982). From Ace to Zombie: Some explorations in the language of personality. In C. D. Spielberger \& J. N. Butcher (Eds.), Advances in Personality Assessment, Vol. 1, (pp. 203-234). Hillsdale, N.J.: Erlbaum.

Grilo, C. M., Sanislow, C. A., Skodol, A. E., Gunderson, J. G., Stout, R. L., Bender, D. S., et al. (2007). Longitudinal diagnostic efficiency of DSM-IV criteria for borderline personality disorder: A 2-year prospective study. The Canadian Journal of Psychiatry, 52, 357-362.

Haigler, E. D. \& Widiger, T. A. (2001). Experimental manipulation of NEO PI-R items. Journal of Personality Assessment, 77, 339-358.

Hare, R.D. (2003). Hare Psychopathy Checklist Revised (PCL-R). Technical manual. North Tonawanda, NY: Multi-Health Systems, Inc.

Hilsenroth, M., Menaker, J., Peters, E., \& Pincus, A. (2007). Assessment of borderline pathology using the Inventory of Interpersonal Problems Circumplex Scales (IIPC): A comparison of clinical samples. Clinical Psychology \& Psychotherapy, 14, 365-376.

Hogan, J. \& Holland, B. (2003). Using theory to evaluate personality and job performance relations: A socioanalytic perspective. Journal of Applied Psychology, 88, 100-112.

Hong, J. P., Samuels, J., Bienvenu, O. J., Hsu, F. C., Eaton, W. W., Costa, P. T., \& Nestadt, G. (2005). The longitudinal relationship between personality disorder dimensions and global functioning in a community-residing population. Psychological Medicine, 35, 891-895.

Horowitz, L. M, Alden, L. E., Wiggins, J. S., \& Pincus, A. L. (2000). Inventory of Interpersonal Problems. San Antonio, TX: Psychological Corporation. 
Horowitz, L. M. \& Wilson, K. R. (2005). Interpersonal motives and personality disorders. In S. Strack (Ed.), Handbook of personology and psychopathology (pp. 495-510). Hoboken, NJ: John Wiley \& Sons Inc.

Hoyle, R.H., Fejfar, M.C., \& Miller, J.D. (2000). Personalty and sexual risk-taking: A quantitative review. Journal of Personality, 68, 1203-1231.

Huo-Liang, G. (2006). Personality and crime: A meta-analysis of studies on criminals' personality. Chinese Mental Health Journal, 20, 465-468.

Hyler, S. E. (1994). Personality Diagnostic Questionnaire-4 (PDQ-4). New York: New York State Psychiatric Institute.

Hyler, S. E., Riedler, R. O., Williams, J. B., Spitzer, R. L., \& Hendler, J. (1989). A comparison of clinical and self-report diagnoses of DSM-III personality disorders in 552 patients. Comprehensive Psychiatry, 30, 170-178.

John, O. P., \& Srivastava, S. (1999). The Big Five trait taxonomy: History, measurement, and theoretical perspectives. In L. A. Pervin \& O. P. John (Eds.), Handbook of personality. Theory and research ( $2^{\text {nd }}$ ed., pp. 102-138). NY: Guilford.

Johnson, J. G., First, M. B., Cohen, P., Skodol, A. E., \& Kasen, S., \& Brook, J. S. (2005). Adverse outcomes associated with personality disorder not otherwise specified in a community sample. American Journal of Psychiatry, 162, 1926-1932 .

Johnson, J. G., Rabkin, J. G., Williams, J. B. W., Remien, R. H., \& Gorman, J. M. (2000). Difficulties in interpersonal relationships associated with personality disorders and Axis I disorders: A community-based longitudinal investigation. Journal of Personality Disorders, 14, 42-56.

Kendler, K. S., Gardner, C. O., \& Prescott, C. A. (2006). Toward a comprehensive developmental model for major depression in men. American Journal of Psychiatry, 163, 115-124.

Kennedy, J.A. (2003). Mastering the Kennedy Axis V: A new psychiatric assessment of patient functioning. Washington, D.C.: American Psychiatric Publishing.

Klonksy, E.D., Oltmanns, T.F., \& Turkheimer, E. (2002). Informant-reports of personality disorder: Relation to self-reports and future research directions. Clinical Psychology: Science and Practice, 9, 399-311.

Kosek, R. B. (1998). Couples Critical Incidents Checklist: A construct validation study. Journal of Clinical Psychology, 54, 785-794.

Krueger, R. F., Skodol, A. E., Livesley, W. J., Shrout, P. E., Huang, Y. (2008). Synthesizing dimensional and categorical approaches to personality disorders: Refining the research agenda for DSM-V Axis II. In H. U. Wittchen, P. J.

Sirovatka, J. E. Jelzer, H. C. Kraemer, R. F. Krueger, et al. (Eds.). Dimensional approaches in diagnostic classification: Refining the research agenda for DSM-V (pp. 85-99). Washington, D. C.: American Psychiatric Association.

Livesley, W.J. (2001). Conceptual and taxonomic issues. In W.J. Livesley (Ed.), Handbook of personality disorders: Theory, research, and treatment (pp. 3-38). NY: Guilford.

Livesley, W. J. (2007). A framework for integrating dimensional and categorical classifications of personality disorder. Journal of Personality Disorders, 21, 190224.

Lynam, D. R., \& Widiger, T. A. (2001). Using the five factor model to represent the 
DSM-IV personality disorders: An expert consensus approach. Journal of Abnormal Psychology, 110, 401-412.

Lynam, D. R., \& Widiger, T. A. (2007). Using a general model of personality to understand sex differences in the personality disorders. Journal of Personality Disorders, 21, 583-602.

Malouff, J. M. Thorsteinsson, E. B., \& Schutte, N. S. (2005). The relationship between the five-factor model of personality and symptoms of clinical disorders: a metaanalysis. Journal of Psychopathology and Behavioral Assessment, 27, 101-114.

Markon, K. E., Krueger, R. F., \& Watson, D. (2005). Delineating the structure of normal and abnormal personality: An integrative hierarchical approach. Journal of Personality and Social Psychology, 88, 139-157.

Markowitz, J. C. (2005). Interpersonal therapy. In J. M. Oldham, A. E. Skodol \& D. S. Bender (eds.) The American Psychiatric Publishing Textbook of Personality Disorders (pp. 321-334). Arlington, VA: American Psychiatric Publishing.

McCrae, R.R., \& Allik, J. (2002). The five-factor model of personality across cultures. New York: Plenum Publishers.

McCrae, R. R. \& Costa, P. T. (1989). The structure of interpersonal traits: Wiggins's circumplex and the five-factor model. Journal of Personality and Social Psychology, 56, 586-595.

McCrae, R.R., \& Costa, P.T. (2003). Personality in adulthood. A five-factor theory perspective ( $2^{\text {nd }}$ ed.). NY: Guilford.

McCrae, R. R., Lockenhoff, C. E., \& Costa, P. T., Jr. (2005). A step toward DSM-V: Cataloguing personality-related problems in living. European Journal of Personality, 19, 269-286.

McCrae, R.R., Stone, S.V., Fagan, P.J., \& Costa, P.T. (1998). Identifying causes of disagreement between self-reports and spouse ratings of personality. Journal of Personality, 66, 285-313.

McGlashan, T. H., Grilo, C. M., Sanislow, C. A., Ralevski, E., Morey, L. C., Gunderson, J. G., et al. (2005). Two-year prevalence and stability of individual DSM-IV criteria for schizotypal, borderline, avoidant, and obsessive-compulsive personality disorders: Toward a hybrid model of Axis II disorders. American Journal of Psychiatry, 162, 883-889.

Miller, J. D. \& Lynam, D. R. (2003). Psychopathy and the five factor model of personality: A replication and extension. Journal of Personality Assessment, 81, 168-178.

Millon, T., Davis, R. D., Millon, C. M., Wenger, A. W., Van Zuilen, M. H., Fuchs, M., et al. (1996). Disorders of personality. DSM-IV and beyond. NY: John Wiley \& Sons.

Morey, L. C., Waugh, M. H., \& Blashfield, R. K. (1985). MMPI scales for DSM-III personality disorders: Their derivation and correlates. Journal of Personality Assessment, 49, 245-251.

Morey, L. C., Alexander, G. M., \& Boggs, C. (2005). Gender and personality disorder. In J. Oldham, A. Skodol \& D. Bender (Eds.), Textbook of Personality Disorders (pp. 541-554). Washington, D C: American Psychiatric Press.

Mullins-Sweatt, S. N. \& Widiger, T. A. (2006). The five-factor model of personality disorder: A translation across science and practice. In R. F. Krueger \& J. L. 
Tackett (eds). Personality and Psychopathology: Building Bridges. (pp. 39-70). New York, NY: Guilford Publications.

Munafo, M.R., Clark, T., \& Flint, J. (2005). Promise and pitfalls in the meta-analysis of genetic association studies: A response to Sen and Schinka. Molecular Psychiatry, $10,895-897$.

Nigg, J. T., John, O. P., Blaskey, L. G., Huang-Pollock, C. L., Willicut, E. G., Hinshaw, S. P., \& Pennington, B. (2002). Big Five dimensions and ADHD symptoms: Links between personality traits and clinical symptoms. Journal of Personality and Social Psychology, 83, 451-469.

Norman, W.T. (1967). 2800 personality trait descriptors: Normative operating characteristics for a university population. Department of Psychology, University of Michigan, Ann Arbor.

O'Connor, B. P. (2005). A search for consensus on the dimensional structure of personality disorders. Journal of Clinical Psychology, 61, 323-345.

Ostendorf, F. (2000). Personality disorders and the five-factor model of personality: A meta-analysis. European Psychiatry, 15, 226s-227s.

Ozer, D. J. \& Benet-Martinez, V. (2006). Personality and the prediction of consequential outcomes. Annual Review of Psychology, 57, 401-421.

Parker, G., Both, L., Olley, A., Hadzi-Pavlovic, D., Irvine, P., \& Jacobs, G. (2002). Defining disordered personality functioning. Journal of Personality Disorders, $16,503-522$.

Parker, G., Hadzi-Pavlovic, D., Both, L., Kumar, S., Wilhelm, K., \& Olley, A. (2004). Measuring disordered personality functioning: To love and to work reprised. Acta Psychiatrica Scandanavica, 110, 230-39.

Piedmont, R. L. \& Piedmont, R. I. (1996). Couples Critical Incidents Check List, manual. Baltimore, MD: Author.

Piedmont, R. L., Sherman, M. F., \& Barrickman, L. (2000). Brief psychosocial assessment of a clinical sample: An evaluation of the Personal Problems Checklist for Adults. Assessment, 7, 177-187.

Pincus, A. L., \& Gurtman, M. B. (2006). Interpersonal theory and the interpersonal circumplex: Evolving perspectives on normal and abnormal personality. In S.

Strack (Ed.), Differentiating normal and abnormal personality (2nd ed., pp. 83-111). New York: Springer.

Ready, R. E., \& Clark, L. A. (2002). Correspondence of psychiatric patient and informant ratings of personality traits, temperament, and interpersonal problems.

Psychological Assessment, 14, 39-49.

Reynolds, S. K. \& Clark, L. A. (2001). Predicting dimensions of personality disorders from domains and facets of the five-factor model. Journal of Personality, 69, 199-222.

Roberts, B. W., \& DelVecchio, W. F. (2000). The rank-order consistency of personality traits from childhood to old age: A quantitative review of longitudinal studies. Psychological Bulletin, 126, 3-25.

Ross, S. R., Lutz, C. J., \& Bailley, S. E. (2002). Positive and negative symptoms of schizotypy and the five-factor model: A domain and facet level analysis. Journal of Personality Assessment, 79, 53-72.

Saroglou, V. (2002). Religion and the five factors of personality: A meta-analytic review. Personality and Individual Differences, 32, 15-25. 
Saucier, G., \& Goldberg, L. R. (2002). Assessing the Big Five: Applications of 10 psychometric criteria to the development of marker scales. In B. de Raad \& M. Perugini (Eds.), Big Five assessment (pp. 29-58). Goettingen, Germany: Hogrefe \& Huber.

Saulsman, L. M. \& Page, A. C. (2004). The five-factor model and personality disorder empirical literature: A meta-analytic review. Clinical Psychology Review, 23, $1055-1085$.

Schinka, J. A. (1985). Personal Problems Checklist for Adults. Odessa, FL: Psychological Assessment Resources.

Schinka, J. A, Busch, R. M., \& Robichaux-Keene, N. (2004). A meta-analysis of the association between the serotonin transporter gene polymorphism (5-HTTLPR) and trait anxiety. Molecular Psychiatry, 9, 197-202.

Sen, S., Burmeister, M., \& Ghosh, D. (2004). Meta-analysis of the association between a serotonin transporter polymorphism (5-HTTLPR) and anxiety-related personality traits. American Journal of Medical Genetics Part B, 127B, 85-89.

Shea, M. T. (1992). Some characteristics of the Axis II criteria sets and their implications for assessment of personality disorders. Journal of Personality Disorders, 6, 377381.

Shedler, J. \& Westen, D. (1998). Refining the measurement of Axis II: A Q-sort procedure for assessing personality pathology. Assessment, 5, 333-353.

Sholevar, G. P. (2005). Family therapy. In J. M. Oldham, A. E. Skodol \& D. S. Bender (eds.) The American Psychiatric Publishing Textbook of Personality Disorders (pp. 359-374). Arlington, VA: American Psychiatric Publishing.

Skodol, A. E., Gunderson, J. G., McGlashan, T. H., Dyck, I. R., Stout, R.L., Bender, D. S., et al. (2002). Functional impairment in patients with schizotypal, borderline, avoidant, or obsessive-compulsive personality disorder. American Journal of Psychiatry, 159, 276-283.

Skodol, A. E., Pagano, M. E., Bender D. S., Shea, M. T, Gunderson, J. G., Yen, S. et al. (2005). Stability of functional impairment in patients with schizotypal, borderline, avoidant, or obsessive-compulsive personality disorder over two years.

Psychological Medicine, 35, 443-451.

Smith, T. L. \& Benjamin, L. S. (2002). The functional impairment associated with personality disorders. Current Opinions in Psychiatry, 15,135-41.

Smith, T. W., \& MacKenzie, J. (2006). Personality and risk of physical illness. Annual Review of Clinical Psychology, 2, 435-467.

Soloff, P. H. (2005). Somatic treatments. In J. M. Oldham, A. E. Skodol \& D. S. Bender (eds.) The American Psychiatric Publishing Textbook of Personality Disorders (pp. 387-404). Arlington, VA: American Psychiatric Publishing.

Steel, P., Schmidt, J., \& Schultz, J. (2008). Refining the relationship between personality and subjective well-being. Psychological Bulletin, 134, 138-161.

Suls, J., \& Bunde, J. (2005). Anger, anxiety, and depression as risk factors for cardiovascular disease: the problems and implications of overlapping affective dispositions. Psychological Bulletin, 131, 260-300.

Tackett, J. L., Silberschmidt, A. L., Krueger, R. F., \& Sponheim, S. R. (in press). A dimensional model of personality disorder: Incorporating DSM cluster A characteristics. Journal of Abnormal Psychology. 
Taylor, G. J., \& Bagby, R. M. (2004). New trends in alexithymia research. Psychotherapy and Psychosomatics, 73, 68-77.

Trobst, K. A., Ayearst, L. E., \& Salekin R. T. (2004). Where is the personality in personality disorder assessment? A comparison across four sets of personality disorder scales. Multivariate Behavioral Research, 39, 231-271.

Van der Oord, S., Prins, P. J. M., Oosterlaan, J. \& Emmelkamp, P. M. G. (2007). Efficacy of methylphenidate, psychosocial treatments and their combination in school-aged children with ADHD: A meta-analysis. Clinical Psychology Review, 28, 783-800.

Verheul, R. (2005). Clinical utility for dimensional models of personality pathology. Journal of Personality Disorders, 19, 283-302.

Vittengl, J. R., Clark, L. A., \& Barrett, J. R. (2003). Interpersonal problems, personality pathology, and social adjustment after cognitive therapy for depression.

Psychological Assessment, 15, 29-40.

Warner, M. B., Morey, L . C., Finch, J. F., Gunderson, J. G., Skodol, A. E., Sanislow, C. A., et al. (2004). The longitudinal relationship of personality traits and disorders. Journal of Abnormal Psychology, 113, 217-227.

Widiger, T. A., \& Boyd, S. (in press). Assessing personality disorders. In J. N. Butcher (Ed.), Oxford handbook of personality assessment ( ${ }^{\text {rd }}$ ed.). New York: Oxford University Press.

Widiger, T. A. \& Costa, P. T. (1994). Personality and personality disorders. Journal of Abnormal Psychology, 103, 78-91.

Widiger, T. A. \& Costa, P. T. (2002). Five-factor model personality disorder research. In T. A. Widiger \& P. T. Costa (Eds.) Personality disorders and the five-factor model of personality ( $2^{\text {nd }}$ ed., pp. 59-87). Washington, D. C.: American Psychological Association.

Widiger, T. A., Costa, P. T., \& McCrae, R. R. (2002). A proposal for Axis II: Diagnosing personality disorders using the five factor model. In P. T. Costa \& T. A. Widiger (Eds.), Personality disorders and the five factor model of personality (2nd ed., pp.431-456). Washington, DC: American Psychological Association.

Widiger, T. A., \& Lowe, J. (2007). Five factor model personality disorder assessment. Journal of Personality Assessment, 89, 16-29.

Widiger, T. A., \& Simonsen, E. (2005). Alternative dimensional models of personality disorder: Finding a common ground. Journal of Personality Disorders, 19, 110130.

Widiger, T. A., \& Trull, T. J. (2007). Plate tectonics in the classification of personality disorder: Shifting to a dimensional model. American Psychologist, 62, 71-83.

Wiggins, J. S. (2003). Paradigms of personality assessment. New York: Guilford Press.

Wiggins, J. S. \& Pincus, A. L. (1989). Conceptions of personality disorders and dimensions of personality. Psychological Assessment, 1, 305-316.

Wiggins, J. S. \& Pincus, A. L. (2002). Personality Structure and the Structure of Personality Disorders. In T. A. Widiger \& P. T. Costa (Eds.) Personality disorders and the five-factor model of personality ( $2^{\text {nd }}$ ed., pp.103-124).

Washington, D. C.: American Psychological Association.

Yamagata, S., Suzuki, A., Ando, J., Ono, Y, Kijima, N, Yoshimura, K, et al. (2006). Is the genetic structure of human personality universal? A cross-cultural twin study 
from North America, Europe, and Asia. Journal of Personality and Social Psychology, 90, 987-998.

Zanarini, M. C., Frankenburg, F. R., Reich, D. B., Silk, K. R., Hudson, J. I., \& McSweeney, L. B. (2007). The subsyndromal phenomenology of borderline personality disorder: A 10-year follow-up study. American Journal of Psychiatry, 164, 929-935. 
Vita

Stephanie N. Mullins-Sweatt

Place of Birth: Harlan, Kentucky

Date of Birth: February 16, 1979

Education

Morehead State University

Morehead, KY

M.A., Clinical Psychology

May, 2003

University of Kentucky

B.S., Psychology

Lexington, $\mathrm{KY}$

May, 2001

$\underline{\text { Professional Positions }}$

Assistant Director

Jesse G. Harris, Jr. Psychological Services Center

July 2006 to July 2007

University of Kentucky

Supervisor: Dr. David Susman

Healthy Relationships Group Co-Leader

July 2006 to April 2007

Hope Center

Supervisor: Dr. David Susman

Assessment Coordinator

Jesse G. Harris, Jr. Psychological Services Center

July 2005 to July 2006

University of Kentucky

Supervisor: Dr. David Susman

Dialectical Behavior Therapy Group Co-Leader

April 2005 to May 2006

Jesse G. Harris, Jr. Psychological Services Center

University of Kentucky

Supervisor: Dr. Ruth Baer

Student Therapist

Jesse G. Harris, Jr. Psychological Services Center

University of Kentucky

Supervisor: Drs. Ruth Baer, Tamara Brown, Mary Beth McGavran, Martha Wetter

Practicum Student

May 2003 to August 2003

Kentucky Comprehensive Sex Offender Pre-sentencing Evaluation

Supervisor: Dr. Nancy Smith

Student Therapist

January 2003 to August 2003

University Counseling Center 
Morehead State University

Supervisor: Dr. David Olson

Student Therapist

Eastern Kentucky Correctional Complex

May 2002 to August 2002

Supervisor: Dr. Charles Morgan

Ad Hoc Reviewer

Journal of Abnormal Psychology

Journal of Personality Disorders,

Course Instructor

Summer, 2007

Personality Psychology

Department of Psychology, University of Kentucky

Course Instructor

Summer, 2006

Psychology of Adjustment

Department of Psychology, University of Kentucky

Teaching Assistant

Introduction to Clinical Interviewing

Department of Psychology, University of Kentucky

Teaching Assistant

Research in Personality

Department of Psychology, University of Kentucky

Teaching Assistant

Spring Semester, 2003

Adult Personality Assessment

Department of Psychology, Morehead State University

Teaching Assistant

Fall Semester, 2002

Intellectual Assessment

Department of Psychology, Morehead State University

Teaching Assistant

Psychology of Personality

Department of Psychology, Morehead State University

Teaching Assistant

Introduction to Psychology and Physiological Psychology

Fall Semester, 2001

Department of Psychology, Morehead State University

Scholastic and Professional Honors

Dissertation Year Fellowship, University of Kentucky

2007-2008

Outstanding Scientist-Practitioner Award, University of Kentucky 
Excellent Clinical Service Award, University of Kentucky

Paul Hager Graduate Research Award, Kentucky Psychological Association 2006

Student Merit Travel Award, University of Kentucky

2004-2007

Violence against Women Petit Research Grant, University of Kentucky

2004-2005

Outstanding Clinical Graduate Student, Morehead State University

2003

Phi Beta Kappa, University of Kentucky

2001

Undergraduate Research and Creativity Award, University of Kentucky

2000-2001

\section{$\underline{\text { Professional Publications }}$}

Mullins-Sweatt, S. N. (in press). Examining the relationship between personality trait and disorder scales: A graphical approach. In I. V. Halvorsen \& S. N. Olsen (eds). New Research on Personality Disorders. Hauppauge, NY: Nova Publishers, Inc.

Mullins-Sweatt, S. N. \& Widiger, T. A. (in press). Comparative validity of SWAP-200 Five-Factor model scales. Psychological Assessment.

Mullins-Sweatt, S. N. \& Widiger, T. A. (in press). Diagnosis and assessment of personality disorders: The DSM-IV-TR and beyond. In P. J. Corr \& G. Matthews (eds). Handbook of Personality. NY: Cambridge University Press.

Mullins-Sweatt, S. N. \& Widiger, T. A. (2007). Millon's dimensional model of personality disorders: A comparative study. Journal of Personality Disorders, 21, 42-57.

Mullins-Sweatt, S. N. \& Widiger, T. A. (2007). Understanding the Shedler and Westen Assessment Procedure from the perspective of general personality structure. Journal of Abnormal Psychology, 116, 618-623.

Widiger, T.A., \& Mullins-Sweatt, S. N. (2008). Classification. In M. Hersen \& A.M. Gross (Eds.), Handbook of clinical psychology. Volume 1. Adults, (pp. 341-370). NY: John Wiley \& Sons.

Widiger, T. A. \& Mullins-Sweatt, S. N. (2007). Mental disorders as discrete clinical conditions: Dimensional versus categorical classification. In M. Hersen, S. M. Turner, \& D. C. Beidel. (eds). Adult Psychopathology and Diagnosis ( $5^{\text {th }}$ ed., pp.3-33). NY: John Wiley \& Sons.

Mullins-Sweatt, S. N., Jamerson, J. E., Samuel, D. S., Olson, D. R., \& Widiger, T. A. (2006). Psychometric properties of an abbreviated instrument of the five-factor model. Assessment, 13 (2), 119-137.

Mullins-Sweatt, S. N. \& Widiger, T. A. (2006). The five-factor model of personality disorder: A translation across science and practice. In R. F. Krueger \& J. L. Tackett (eds). Personality and Psychopathology (pp. 39-70). NY: Guilford Publications. 
Rauhut, A.S., Mullins, S. N., Dwoskin, L.P. \& Bardo, M.T. (2002). Reboxetine: Attenuation of intravenous nicotine self-administration in rats. Journal of Pharmacology and Experimental Therapeutics, 303(2), 664-72.

Widiger, T. A. \& Mullins, S. N. (2003). Personality disorders. In A. Tasman, J. Kay, J. A. Lieberman \& M. B. First (Eds.), Psychiatry, (vol. 2, $2^{\text {nd }}$ ed., pp. 1603-1637). Philadelphia, PA: W. B. Saunders.

Widiger, T. A. \& Mullins-Sweatt, S. N. (2005). Categorical and dimensional models of personality disorder. In J. M. Oldham, A. E. Skodol \& D. S. Bender (eds.) The American Psychiatric Publishing Textbook of Personality Disorders (pp. 35-53). Arlington, VA: American Psychiatric Publishing.

Widiger, T. A., Mullins-Sweatt, S. N., \& Anderson, K. (2005). Personality and depression in women. In C. Keyes \& S. Goodman (eds.) Handbook for the study of women and depression: Views from social, behavioral, and biomedical sciences (pp. 176-198). NY: Cambridge University Press.

Widiger, T. A. \& Mullins-Sweatt, S. N. (2004). Typology of maritally violent men. Journal of Interpersonal Violence, 19 (12), 1396-1400.

Mullins-Sweatt, S. N., Smit, V., Verheul, R. Oldham, J., \& Widiger, T. A. (under review). Dimensions of personality: Clinicians' perspective.

Mullins-Sweatt, S. N. \& Widiger, T. A. (under review). Clinicians' judgments of the utility of the DSM-IV and Five-Factor models for personality disordered patients.

Mullins-Sweatt, S. N. \& Widiger, T. A. (2007, October). Comparative validity of SWAP200 five-factor model scales. Poster presented at the annual meeting of the Society for Research in Psychopathology.

Mullins-Sweatt, S. N. \& Widiger, T. A. (2007, March). Understanding the Shedler and Westen assessment procedure from the perspective of general personality structure. Paper presented at the meeting of the Kentucky Psychological Association.

Mullins-Sweatt, S. N. \& Widiger, T. A. (2006, April). Understanding the Shedler and Westen assessment procedure from the perspective of general personality structure. Poster presented at the meeting of the Kentucky Psychological Association.

Palmgreen, P. C., Lorch, E. P., Stephenson, M. T., Donohew, L., Hoyle, R., \& Sweatt, S. N. (2005, November). Effect of the Office of National Drug Control Policy's marijuana initiative campaign on at-risk youth. Paper presented at the annual meeting of Public Health Education and Health Promotion. 
Mullins-Sweatt, S. N., Jamerson, J. E., Widiger, T. A., \& Olson, D. R. (2004, October). Psychometric properties and implications of an abbreviated measure of the fivefactor model. Poster presented at the annual meeting of the Society for Research in Psychopathology.

Mullins-Sweatt, S. N., Jamerson, J. E., Widiger, T. A., \& Olson, D. R. (2004, January). Psychometric properties and implications of an abbreviated measure of the fivefactor model. Poster presented at the annual meeting of the Association of Research in Personality.

Mullins-Sweatt, S. N. \& Olson, D. R. (2003, October). Personality disorders and the five-factor model: A subclinical approach. Poster presented at the annual meeting of the Kentucky Psychological Association.

Mullins, S. N., Rauhut, A. S., Dwoskin, L. P., and Bardo, M. T. (2001, May). Acute and chronic effects of reboxetine on nicotine self-administration in rats. Poster presented at the annual meeting of the Midwestern Psychological Association.

Mullins, S. N., Widiger, T. A., and Lynam, D. R. (2001, March). Personality disorders, maladaptive variants of personality traits: An expert consensus approach. Poster presented at the meeting of the National Conference for Undergraduate Research.

Mullins, S. N., Rauhut, A. S., Dwoskin, L. P., and Bardo, M. T. (2000, November). Acute and chronic effects of reboxetine on nicotine self-administration in rats. Poster presented at the meeting of Kentucky Academy of Science. 